\title{
Advances in Chinese Dual-Polarization and Phased-Array Weather Radars: Observational Analysis of a Supercell in Southern China
}

\author{
ChOng Wu, LiPING LiU, AND Xi LiU \\ State Key Laboratory of Severe Weather, Chinese Academy of Meteorological Science, Beijing, and Collaborative \\ Innovation Center on Forecast and Evaluation of Meteorological Disasters, Nanjing University of Information \\ Science and Technology, Nanjing, China \\ GUOCUI LI \\ Shijiazhuang Meteorological Observatory, Shijiazhuang, China \\ CHAO CHEN \\ Guangdong Meteorological Observatory, Guangzhou, China
}

(Manuscript received 27 April 2017, in final form 24 June 2018)

\begin{abstract}
In the summer of 2016, one phased-array radar and two polarimetric weather radars, representative of advancing radar technology in use in China, jointly collected data in the Foshan area to study severe convective storms in southern China. After an introduction to the technical characteristics and a verification of the radar calibration, the advantages of the abovementioned dual-polarization and phased-array radars are discussed in terms of an observational analysis of a supercell that occurred on 9 May 2016. The polarimetric signatures within the supercell are associated with specific microphysical processes that can reveal different stages of storm evolution. The hydrometeor classification algorithm is a more straightforward and useful method for nowcasting than conventional algorithms, which makes it favorable for further recommendation in China. During the mature and dissipating stages of this supercell, observations of the phased-array radar show detailed changes on short time scales that cannot be observed by parabolic-antenna radars. The initiation and mergers of new convective cells are found in the peak inflow region, and the formation and dissipation of the hook echo are associated with the relative intensities of inflow and outflow. The abovementioned results demonstrate that the phased-array radar and dual-polarization radars recently developed in China are powerful tools to better understand storm evolution for nowcasting and scientific studies.
\end{abstract}

\section{Introduction}

Since 1998, China has been building a new weather radar network, the China New Generation Doppler Weather Radar (CINRAD), which will be composed of $230 \mathrm{~S}$ - and C-band weather radars by 2020 . CINRAD is equipped with a parabolic antenna with horizontal polarization and can mechanically change its azimuth and elevation to complete a volume scan (nine layers) within $6 \mathrm{~min}$. The reflectivity factor $Z$, radial velocity $V$, and spectrum width $W$ are obtained based on the backscattering and Doppler effect of the hydrometeors. Sophisticated radar algorithms, such as rainfall estimation, mesocyclone and hail detection, and Storm Cell

\footnotetext{
Corresponding author: Liping Liu, liulp@cma.gov.cn
}

Identification and Tracking, have been developed for the WSR-88D radar network in the United States (Crum and Alberty 1993; Johnson et al. 1998; Stumpf et al. 1998; Fulton et al. 1998; Witt et al. 1998). However, limited by its scanning period and vertical coverage, it is still a challenge for CINRAD to observe mesogamma-scale (Orlanski 1975) severe storms that develop and dissipate rapidly. On 1 June 2015, a downburst hit the Yangtze River in Jianli County of Hubei Province, producing gale-force winds reaching 12 on the Beaufort scale. The Eastern Star, a cruise ship that was passing this area, capsized, and 442 people died (Meng et al. 2016; Zheng et al. 2016). One year later on 23 June 2016, an EF4 tornado accompanied by hailstones hit Yancheng in Jiangshu Province, resulting in 99 fatalities and 846 injured (Zhang et al. 2016). For the two destructive storms 
mentioned above, for various reasons, forecasters using CINRAD products failed to issue any timely warnings. Improving the observational accuracy and spatialtemporal resolutions of weather radars is a critical issue for the monitoring and nowcasting of severe weather events.

Weather radars that use phased-array and/or dualpolarization technologies can provide substantial insight relevant to the interests of meteorologists tasked with identifying and forecasting severe convective storms. The volume scan efficiency is greatly enhanced in phased-array radars via the "electronic scanning" approach with agile beam steering and multibeam scanning. The restriction of parabolic-antenna radars caused by the mechanical servo system and the nonzero dwell time (i.e., pulse averaging time) is reduced ( $\mathrm{Yu}$ et al. 2007; Heinselman et al. 2008; Heinselman and Torres 2011; Yoshikawa et al. 2013). For dual-polarization radars, the similarities and differences between data collected from two orthogonal channels provide additional information about hydrometeor composition and characteristics (Zrnić and Ryzhkov 1999). Observations of the differential reflectivity $Z_{\mathrm{DR}}$, differential phase $\Phi_{\mathrm{DP}}$, specific differential phase $K_{\mathrm{DP}}$, depolarization ratio $L_{\mathrm{DR}}$, and cross-correlation coefficient $\rho_{\mathrm{hv}}$ can improve the performance of radar algorithms, especially for quantitative precipitation estimations and hydrometeor classifications. Because the two abovementioned techniques are not mutually exclusive, dual-polarization technology can be used with parabolic and phased-array antennas (Zhang et al. 2009).

As early as 2003, a retired Aegis SPY-1 radar was transformed into the National Weather Radar Testbed phased-array radar (NWRT PAR) in the United States and was later used for experimental studies of phasedarray weather radars (Zrnić et al. 2007). An X-band, truck-based, phased-array weather radar (MWR-05XP; Bluestein et al. 2010) has been used to observe severe convective storms since 2005. The MWR-05XP joined the second Verification of the Origins of Rotation in Tornadoes Experiment (VORTEX2), and its observations of tornadic supercells on short time scales were subsequently analyzed (French et al. 2013, 2014). The Atmospheric Imaging Radar (AIR) is an X-band mobile phased-array radar developed by the Advanced Radar Research Center of the University of Oklahoma (Isom et al. 2013). The AIR uses a broad transmit beam and 36 simultaneous receive beams in the vertical direction, obtaining a range-height indicator (RHI) with every pulse. Compared to WSR-88D radars, phased-array weather radars can detect short-lived storms more quickly, which makes phased-array radars more applicable to practical nowcasting and early warnings
(Wurman et al. 2012; Kurdzo et al. 2017). Yussouf and Stensrud (2010) applied phased-array observations at 1-min intervals in their data assimilation system via an ensemble Kalman filter technique, and it took approximately $15 \mathrm{~min}$ to establish a storm using their model. By contrast, assimilating the WSR-88D observations resulted in slower-than-observed storm development (30-60 min) in the model (Snyder and Zhang 2003; Zhang and Sun 2004). Moreover, the time interval of a volume scan for the performance of a real-time precipitation estimation algorithm (Anagnostou and Krajewski 1999) is not negligible, and rapid-scan observations by phased-array radar are helpful in reducing accumulation errors. From 2009 to 2013, all the WSR-88D weather radars in the United States were upgraded to dual-polarization radars accompanied by algorithm upgrades in storm early warning, tornado identification, precipitation estimation, and hydrometeor classification (Ryzhkov et al. 2005; Park et al. 2009; Elmore 2011; Schuur et al. 2012; J. Zhang et al. 2011; Snyder and Ryzhkov 2015). Currently, the next-generation weather radar being developed is the Multifunction Phased Array Radar, which combines the advantages of phased-array and dual-polarization systems for weather targets; in addition, it can be used for aircraft surveillance. Because the measurement bias of polarimetric variables changes with beam pointing direction for the widely used planar array antenna, Zrnić et al. (2017) proposed a calibration plan for a planar phased-array polarimetric radar called the Advanced Technology Demonstrator. Another polarimetric phased-array radar using a cylindrical columnar antenna has been proposed by G. Zhang et al. (2011). This type of antenna can also maintain an adequate accuracy of the dual-polarization system while exploiting the high spatiotemporal resolution from the phased-array system (Saeidi-Manesh and Zhang 2017; Fulton et al. 2017).

In China, the first S-band phased-array weather radar prototype was transformed from an early warning radar for military purposes in 2007 (Zhang and Liu 2011). A mobile X-band phased-array weather radar (XPAR) with narrow beamwidth and multiple scanning modes was subsequently developed by the Chinese Academy of Meteorological Sciences for the observation of convective storms in 2012. The XPAR uses an adjustable vertical beam $\left(1^{\circ}-4^{\circ}\right.$ in width) on transmit and simultaneously receives $1-4$ pencil beams, which means its scanning strategy is different from that of MWR-05XP. From 2013 to 2014, XPAR was deployed in the Guangdong, Anhui, and Sichuan Provinces for factory testing and calibration. Its observations in different operational modes were compared to that of a C-band polarimetric radar at the same position (Wu et al. 2014b; 
Liu et al. 2014, 2015). However, severe storms such as supercells and squall lines had not yet been observed. Then, XPAR joined the Southern China Monsoon Rainfall Experiment (SCMREX; Luo et al. 2017) and was deployed in the Foshan area for severe weather observations during the prerainy seasons in 2016 and 2017. Meanwhile, the pilot project of the polarimetric upgrade was also completed for CINRAD in Guangdong Province.

On 9 May 2016, a supercell with gale winds and hailstones was simultaneously observed by XPAR and nearby polarimetric radars. This paper is the first detailed investigation of the observational ability of the phased-array and dual-polarization radars that have recently been developed in China. Compared with a polarimetric radar equipped with a parabolic antenna, XPAR provides observations with much higher temporal and spatial resolutions. The polarimetric signatures and hydrometeor classification algorithm (HCA) output provide more details about the microphysics processes and storm evolution, which, in a sense, extend the application scope of such radar products compared to those based on only $Z$ or $V$. The results demonstrate the significance of high-resolution and polarimetric observations by the phased-array and dual-polarization radars for nowcasting and scientific studies in China.

This paper first introduces the instruments and analysis methods in section 2. The advantages of dualpolarization and phased-array radars are presented in sections 3 and 4, respectively. The final conclusions and discussion can be found in section 5 .

\section{Data and methods}

\section{a. Characteristics of dual-polarization and phased-array radars in southern China}

The field experiment in this study was part of SCMREX; the locations of the instruments and the topography are illustrated in Fig. 1 . With a $70-\mathrm{km}$ detection radius, XPAR cannot observe the entire evolution process of long-duration convective storms in southern China (e.g., supercells or squall lines). XPAR was deployed northwest of the Pearl River delta $\left(23.15^{\circ} \mathrm{N}, 113.03^{\circ} \mathrm{E}\right)$. Typically, new cells form in the northern mountainous regions of Guangdong and move into this area, where storms mature. An S-band polarimetric radar $\left(\mathrm{SPOL} ; 23.00^{\circ} \mathrm{N}, 113.35^{\circ} \mathrm{E}\right)$ from the Guangzhou Meteorological Bureau and an X-band polarimetric radar $\left(\mathrm{XPOL} ; 23.14^{\circ} \mathrm{N}, 113.01^{\circ} \mathrm{E}\right)$ from the Foshan Meteorological Bureau were located $36 \mathrm{~km}$ southeast and $2.3 \mathrm{~km}$ west of XPAR, respectively. SPOL, with a $230-\mathrm{km}$ detection radius, can observe more features of the storm evolution for a longer

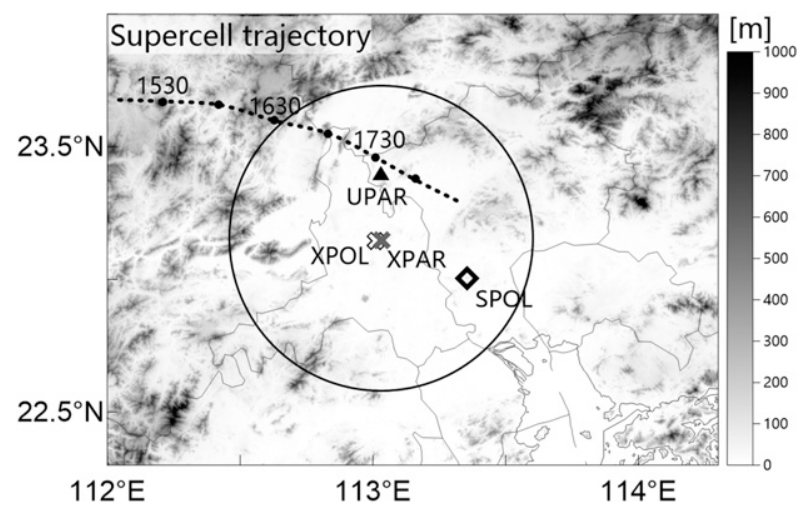

FIG. 1. Distribution of the observational instruments, including SPOL (black rhombus), XPAR (gray cross), XPOL (black cross), and L-band sounding (black triangle). Gray shading represents the topography, and the dotted line denotes the supercell trajectory.

duration. The L-band sounding system at the Qingyuan weather station, which is used to analyze the thermodynamic conditions of the initiation of convection, was located $28 \mathrm{~km}$ north of XPAR.

The XPAR system integration shown in Fig. 2 exhibits significant differences in its antenna design. The parabolic antenna is replaced by a distributed transceiver system with 128 transmit/receive (T/R) components. The digital beamforming (DBF) technique is employed in XPAR to control beam pointing and the beamwidth of multiple simultaneous beams; its major characteristics are listed in Table 1. Two operating modes called fine mode (FM) and quick mode (QM) are used in XPAR; both have 40 elevation angles, $37.5-\mathrm{m}$ range resolution, and use 64 pulses per radial measurement. The major difference between the modes is that the QM uses a fan beam ( $4^{\circ}$ in width) on transmit and four pencil beams $\left(1^{\circ}\right.$ in width) on receive, while the FM uses only one pencil beam for transmitting and receiving. Therefore, the scan efficiency of QM is 4 times greater than that of FM; however, the antenna gain of QM is smaller because the multibeam mode disperses the power of the transmitter. Limited by project funding, XPAR is a one-dimensional phased-array radar where electrical scanning is available only in the vertical direction. The antenna's pitch angle is fixed at $10^{\circ}$, and the scanning cycle is controlled by a horizontal mechanical servo system. A single scan similar to the RHI for an elevation angle from $0.5^{\circ}$ to $39.5^{\circ}$ is conducted at each azimuth, and serial RHI scans within an azimuthal sector constitute the volumetric RHI (VRHI) observations of XPAR. By contrast, SPOL and XPOL, equipped with conventional parabolic antennas, conduct the volumetric plan position indicator (VPPI) scans, providing nine-layer observations according to the volume coverage pattern 21 (VCP21) strategy. Note that SPOL and XPOL 

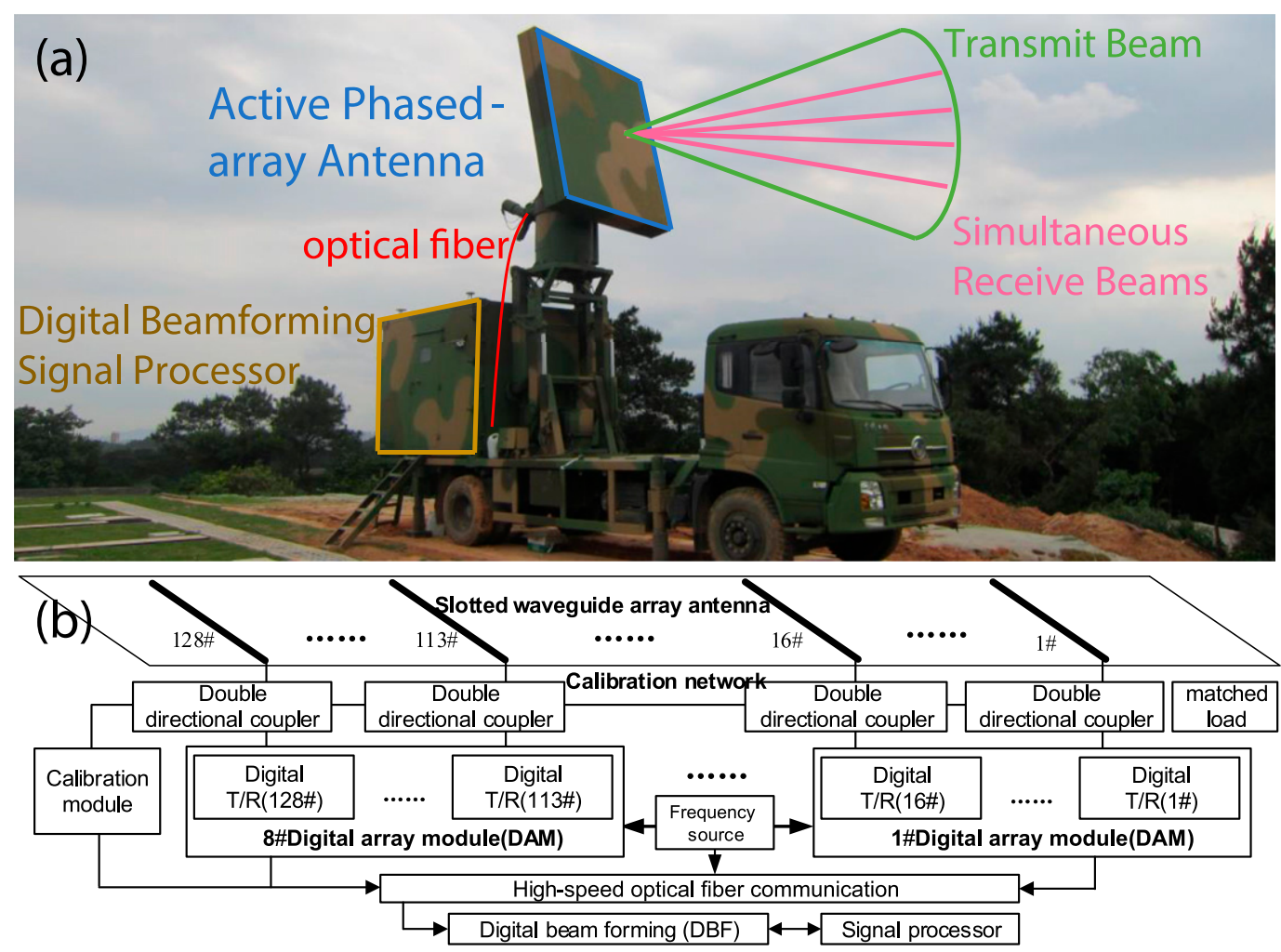

(c)
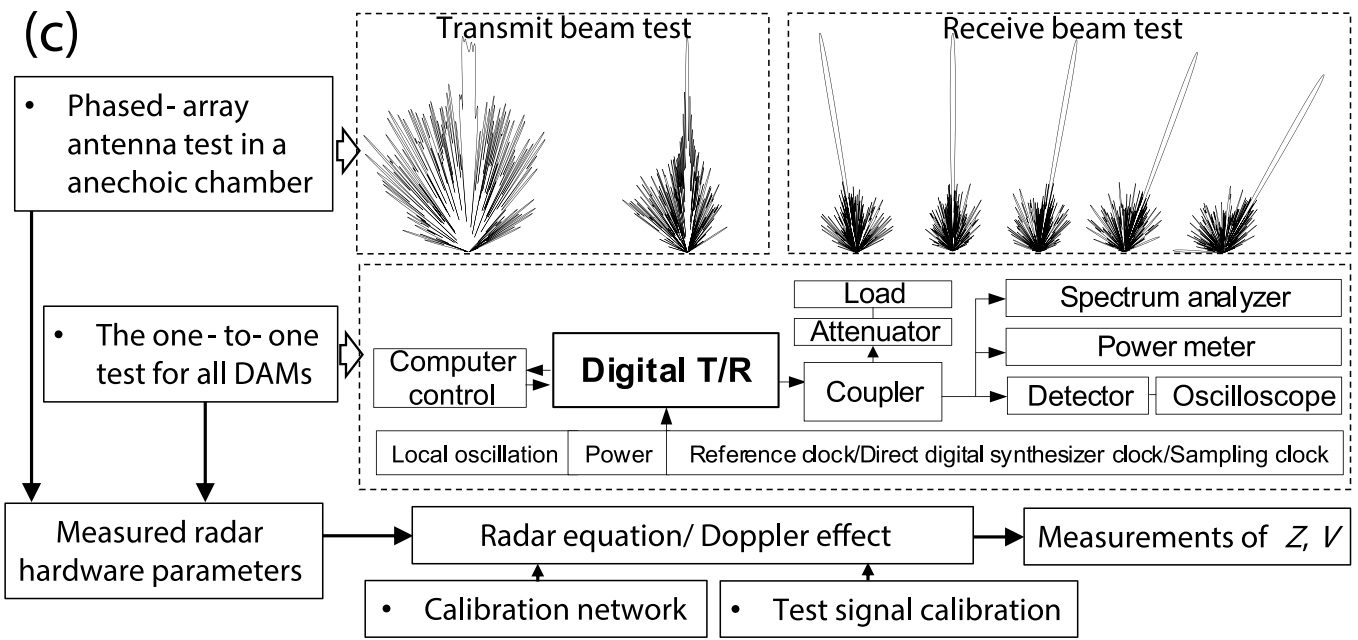

FIG. 2. (a) The active phased-array antenna is installed in the middle of a truck, with a lifting mechanism and fiber communication. (b) The integration of the phased-array system of XPAR. (c) The calibration procedure for XPAR.

are the latest operational polarimetric weather radars in China; their key parameters are also listed in Table 1.

For the supercell studied in this paper, XPAR was operated in FM with a $60^{\circ}$ sector scan to ensure a volumetric update rate of $\sim 1 \mathrm{~min}$, and 75 volumes were obtained during the period of 1640-1740 LST 9 May 2016. Meanwhile, SPOL and XPOL provided measurements at time intervals of 6 and $4 \mathrm{~min}$, respectively. Datasets from XPAR and SPOL were established for the analysis of the radar characteristics and advantages in sections 3 and 4 . Owing to the greater attenuation and more frequent velocity ambiguity of XPOL, its measurements were used only to verify the accuracy of the calibration of XPAR in section 2. Note that XPAR is a horizontally polarized radar and that the absence of $\Phi_{\mathrm{DP}}$ leads to heavy attenuation in its observations. 
TABLE 1. Characteristics of XPAR, XPOL, and SPOL.

\begin{tabular}{|c|c|c|c|}
\hline Parameter & XPAR & XPOL & SPOL \\
\hline Antenna type & 1D phased array & Parabolic & Parabolic \\
\hline Antenna gain & $\begin{array}{l}\text { Emission reception } \\
\text { FM: } 46,44.4 \mathrm{~dB} \\
\text { QM: } 37.8,44.4 \mathrm{~dB}\end{array}$ & Constant $>44.5 \mathrm{~dB}$ & Constant $>45 \mathrm{~dB}$ \\
\hline Frequency & $9370 \mathrm{MHz}$ & $9464 \mathrm{MHZ}$ & $2700 \mathrm{MHZ}$ \\
\hline Beamwidth & $\begin{array}{l}0.61^{\circ} \text { (transmit) } \\
0.88^{\circ} \text { (receive) }\end{array}$ & $\approx 1^{\circ}$ & $\approx 1^{\circ}$ \\
\hline Peak power & $1 \mathrm{~kW}$ & $\geq 75 \mathrm{~kW}$ & $\geq 650 \mathrm{~kW}$ \\
\hline Range resolution & $37.5 \mathrm{~m}$ & $75 \mathrm{~m}$ & $250 \mathrm{~m}$ \\
\hline Range coverage & 70 km (blind space: $5 \mathrm{~km}$ ) & $100 \mathrm{~km}$ & $230 \mathrm{~km}$ \\
\hline Scan mode & $\begin{array}{l}\text { FM: VRHI with } 1 \text { beam } \\
\text { QM: VRHI with } 4 \text { beams }\end{array}$ & VPPI with 1 beam & VPPI with 1 beam \\
\hline Elevation scan capability & $0.5^{\circ}-39.5^{\circ}$ with $1^{\circ}$ step & VCP21 & VCP21 \\
\hline Update time & $\begin{array}{l}\text { FM: } 150 \mathrm{~s} \text { with } 90^{\circ} \text { azimuth } \\
\text { QM: } 150 \mathrm{~s} \text { with } 360^{\circ} \text { azimuth }\end{array}$ & $240 \mathrm{~s}$ & $360 \mathrm{~s}$ \\
\hline Nyquist velocity & $28.8 \mathrm{~m} \mathrm{~s}^{-1}(1800: 1200 \mathrm{~Hz})$ & $11.16-15.42 \mathrm{~m} \mathrm{~s}^{-1}$ & $27.28-31.78 \mathrm{~m} \mathrm{~s}^{-1}$ \\
\hline Polarization & Single $(\mathrm{H})$ & Dual $(\mathrm{H} / \mathrm{V})$ & Dual $(\mathrm{H} / \mathrm{V})$ \\
\hline
\end{tabular}

\section{b. Radar calibration analysis}

The complex system integration of XPAR poses a great challenge for its accurate calibration. Figure $2 \mathrm{c}$ shows the detailed calibration procedures for this radar. A microwave anechoic chamber was used for the exfactory test of the phased-array antenna. The technical parameters of beam shape, sidelobe level, and antenna gain in FM and QM were recorded and verified. Another factor that directly affects the detectivity is the performance of the 128-way T/Rs; therefore, a one-toone test was conducted for each of the digital T/Rs. According to the test flowchart, power, local oscillation, and other signals were input into the $\mathrm{T} / \mathrm{R}$ module to test the pulse width, pulse repetition frequency, and peak power in transmit mode. In the receiver test, signals with different intensity were input into the digital receiver to calculate the linear dynamic range. Because some equipment needed to be dismantled in the T/R test, this work was conducted at the beginning of the outfield experiment and the defective $\mathrm{T} / \mathrm{Rs}$ were replaced by spare parts. In the case of real-time operation, a calibration network, which was connected to the T/Rs via couplers, was used for the T/R calibration. The calibration precision of the signal amplitude and phase is approximately $0.3 \mathrm{~dB}$ and $0.5^{\circ}$, respectively, to guarantee accurate beam forming in the distance field.

After the testing and calibration of each independent subsystem, the abovementioned hardware parameters were used in the signal processor and computer terminal for the $Z / V$ calculation. A special meteorological radar equation was used in XPAR that considered the gain of the pulse compression and the variations in the antenna gain and beamwidth with scan angle (Liu et al. 2015).
By contrast in the calibration procedures of SPOL and XPOL, $Z$ and $V$ adopted the same calibration technology as the WSR-88D radar. Even so, it was necessary to check the accuracy of the radar calibration because there were three radars with different hardware in this field experiment (Liu et al. 2014). Since stratiform precipitation is usually quasi homogeneous in horizontal extent and relatively steady in time, observations of stratiform precipitation during the periods of 1300-1700 LST 20 May and 0600-1400 LST 28 May 2016 were used to calculate the systematic biases. For the two radars at different locations, the values of $Z$ from one radar were matched with the other radar's polar coordinate to find point-to-point data pairs at the same geographical positions and beam volumes (Wu et al. 2014a). The radial velocity is a vector; therefore, only those points along the straight line made by the two stations can be used for comparison. To reduce the impact of attenuation, the $\Phi_{\mathrm{DP}}$ of XPOL was restricted within $5^{\circ}$.

The normalized two-dimensional frequency distributions of $Z$ and $V$ extracted from SPOL and the Zhaoqing radar (a single-polarization radar located $83 \mathrm{~km}$ northwest of SPOL), XPAR and XPOL, and XPAR and SPOL are shown in Figs. 3a-e. The results indicate that all the highfrequency points are distributed nearly along the diagonal $y=x$. The reflectivity factor from XPAR is, on average, $0.8 \mathrm{~dB}$ higher than that from XPOL but $0.37 \mathrm{~dB}$ lower than that from SPOL; little difference is found between SPOL and the Zhaoqing radar. The velocity bias of XPAR is smaller than $0.5 \mathrm{~m} \mathrm{~s}^{-1}$, which is the data-saving resolution of operational radars in China. The abovementioned comparisons demonstrate that XPAR and SPOL are mostly in agreement with each other. 

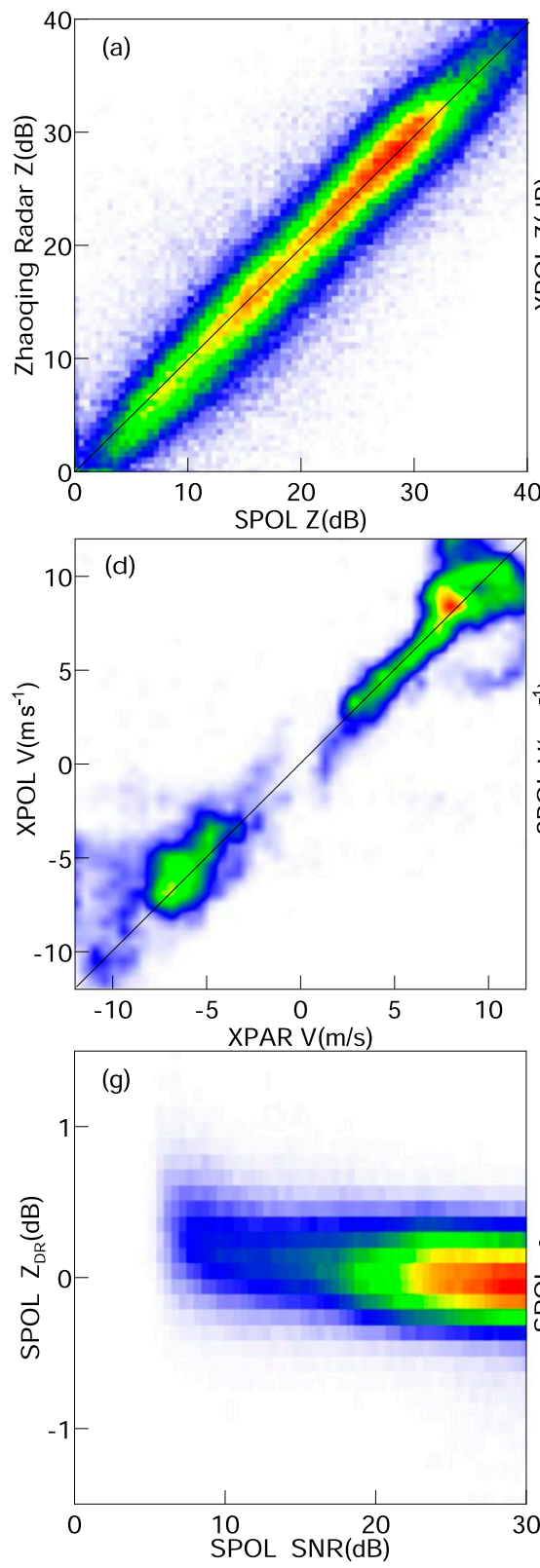
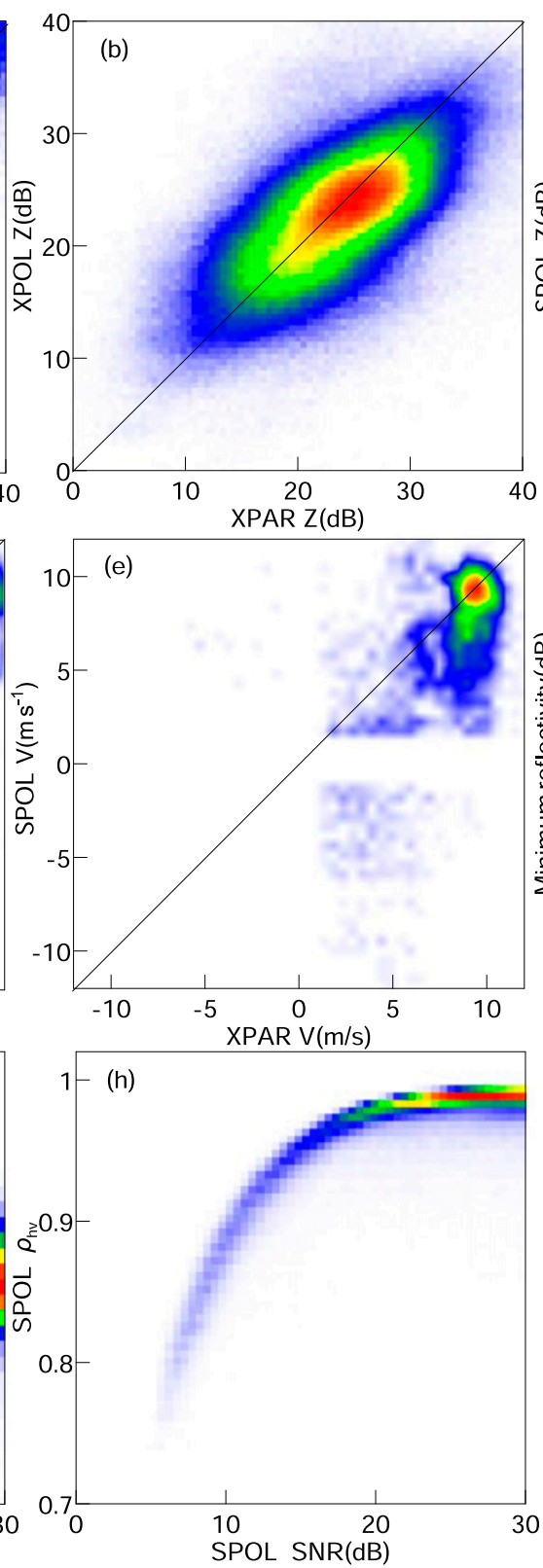
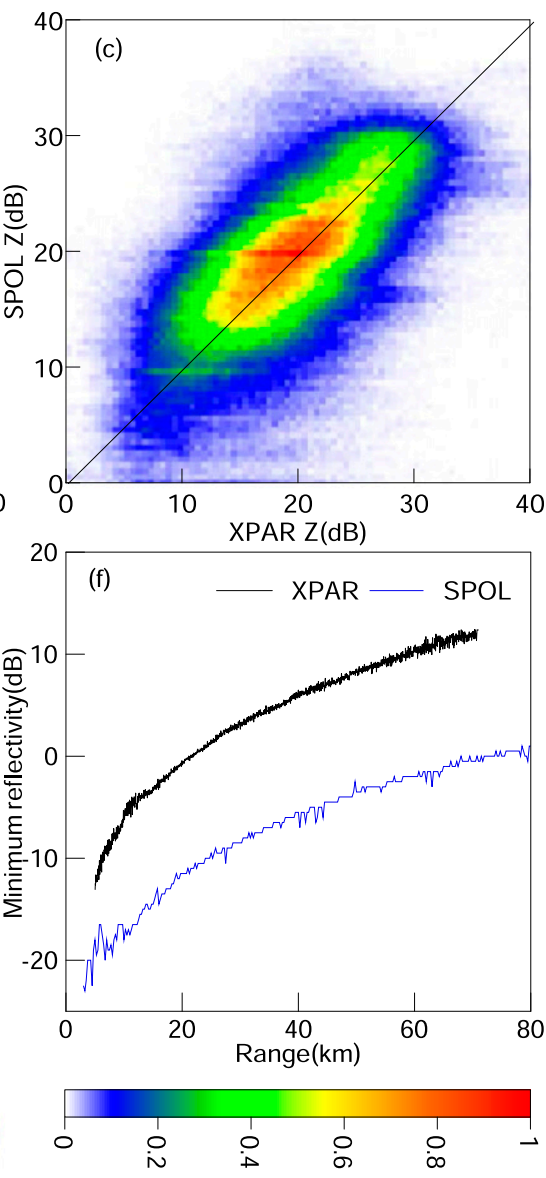

FIG. 3. The radar calibration and performance analysis of SPOL and XPAR. (a) The normalized two-dimensional frequency distributions of $Z$ between SPOL and the Zhaoqing radar. (b),(c) As in (a), but for comparisons of XPAR vs XPOL and XPAR vs SPOL, respectively. (d),(e) As in (b) and (c), but for comparisons of $V$. (f) The minimum detectable reflectivity of XPAR and SPOL with distance. $(\mathrm{g}),(\mathrm{h})$ The normalized frequency distribution plots of SNR- $Z_{\mathrm{DR}}$ and $\mathrm{SNR}-\rho_{\mathrm{hv}}$, respectively, from dry snow echoes of SPOL.

Figure 3f presents the minimum detectable reflectivity with distance, which is used to check the sensitivity of the radar receiver. It is found that the minimum $Z$ from SPOL is $-2.0 \mathrm{~dB} Z$ at a distance of $60 \mathrm{~km}$, whereas the minimum $Z$ from XPAR is $10.47 \mathrm{~dB} Z$ at the same distance. This means that SPOL can provide more detailed information, such as that of drizzle, as a result of its higher sensitivity, and that XPAR cannot detect weak echoes below $10 \mathrm{dBZ}$ over a distance of $60 \mathrm{~km}$.
The calibration accuracy of the polarimetric variables is also critical for dual-polarization radars. Because the VCP21 strategy does not provide vertical pointing observations, dry aggregate snow echoes, where $Z_{\mathrm{DR}}$ is near $0 \mathrm{~dB}$, were extracted from stratiform precipitation to verify the data quality of SPOL. The relationships between the signal-to-noise ratio (SNR) and $Z_{\mathrm{DR}}$ and $\rho_{\mathrm{hv}}$ are investigated in Figs. $3 \mathrm{~g}$ and $3 \mathrm{~h}$, respectively. The results show that $Z_{\mathrm{DR}}$ is evenly distributed around $0 \mathrm{~dB}$ 
and that $\rho_{\text {hv }}$ is nearly greater than 0.99 for those points where SNR $\geq 20 \mathrm{~dB}$, suggesting that SPOL is well designed and calibrated. In the case of SNR $<15 \mathrm{~dB}$, the averaged values of $Z_{\mathrm{DR}}$ and $\rho_{\mathrm{hv}}$ are approximately $0.45 \mathrm{~dB}$ and 0.86 , respectively. Their degradation under weak-signal conditions is considered below.

\section{c. Radar products for supercell analysis}

With the development of Chinese radars similar to the WSR-88D, algorithms developed for use by WSR-88Ds have been widely used by Chinese forecasters. The composite reflectivity (CR) and echo top (ET) algorithms use $Z$ as an input variable, where the maximum value and maximum height in the vertical direction are projected to Cartesian coordinates as the output. The mesocyclone algorithm, by searching for the distance and rotational velocity (one-half of the sum of the absolute velocity of the maximum inflow and the maximum outflow) from adjacent velocity couplets with cyclonic characteristics, divides these couplets into strong mesocyclones, moderate mesocyclones, weak mesocyclones, and weak shear according to the criterion proposed by Andra (1997). Furthermore, the dual-Doppler wind retrieval algorithm is an effective approach that directly provides the horizontal and vertical velocities $(u, v$, and $w)$. However, restricted by reliability, an operational wind retrieval algorithm is not available at present. The three-dimensional wind fields were retrieved from SPOL and the Zhaoqing radar data using NCAR's Custom Editing and Display of Reduced Information in Cartesian Space (CEDRIC) package (Mohr et al. 1986).

With the polarimetric upgrade of CINRAD in southern China, a hydrometeor classification algorithm based on the WSR-88D HCA is being considered for operational application. The HCA is composed of several steps, that is, fuzzy logic operation, confidence vector calculation, melting layer detection, precipitation type identification, and empirical threshold checking (Ryzhkov 2007; Giangrande et al. 2008). Radar echoes are classified into 10 classes: ground clutter (GC) or anomalous propagation (AP), biological scatters (BS), dry aggregated snow (DS), wet snow (WS), crystals of various orientations (CR), graupel (GR), "big drops" (BD), light and moderate rain (RA), heavy rain (HR), and a mixture of rain and hail (RH; Park et al. 2009). Because both the radar hardware and the drop size distributions in China are different from those in the United States (Tang et al. 2014; Chen et al. 2013, 2016; Wen et al. 2016), the membership functions and confidence vector thresholds have been modified based on statistics of routine observations. This optimized HCA has been verified via comparisons with nearby sounding and surface observations (Wu et al. 2018).

\section{Advantages of dual-polarization radar products and signatures in observing supercell evolution}

\section{a. Storm evolution and the performance of Doppler and polarimetric products}

The supercell examined here initiated southwest of Zhaoqing, where the scale of the new cells was only $\sim 10 \mathrm{~km}$. Convective storms continued to develop, eventually forming a mesoscale convective system (MCS) that was $\sim 100 \mathrm{~km}$ in length at approximately 1530 LST. The most vigorous cell within the MCS was located in the right rear (relative to the storm motion) and began showing some lower-tropospheric features common to severe local storms. Figure 4 provides the three-dimensional structures of $Z, V$, and the HCA output of this storm observed by SPOL. From 1530 to 1600 LST, it was difficult to identify the supercell because either $Z$ or the horizontal scale was small compared to the entirety of the MCS. Even though a radial velocity couplet representing the mesocyclone was observed in the first layer, RA, HR, and DS hydrometeors occupied approximately $90 \%$ of the HCA output. Subsequently, this cell rapidly intensified. An obvious mesocyclone was observed in each layer of SPOL at 1630 LST (Fig. 4c), accompanied by a further increased $Z$. Large areas of GR appeared above the melting layer even though the area of RH below was very limited. Then, 18 min later at 1648 LST, a typical hook echo (Markowski 2002), which is a supercell signature, formed at low levels. In Fig. 4d at 1700 LST, the hook echo is visible at a height of $\sim 1 \mathrm{~km}$, along with a strong mesocyclone and large areas of hydrometeors identified as RH. These features were sustained until 1730 LST, when the hook echo rapidly disappeared together with the low-level mesocyclone. The supercell subsequently faded into a multicellular system, which was maintained during the period of 1800-1830 LST before dissipating at 1848 LST.

For this supercell accompanied by hailstones, how to judge the trend of the storm evolution is a key issue for nowcasting. Currently, Chinese forecasters primarily use $\mathrm{CR}, \mathrm{ET}$, and mesocyclone detection algorithms. With the pilot application of polarimetric radars in southern China, the distribution of the RH region from HCA has also been found to reveal characteristics of severe storms. Figure 5 shows the performance of the abovementioned products based on SPOL observations. According to the output of the mesocyclone algorithm in Fig. 5a, weak shear and a weak mesocyclone were primarily found during the time period of 1530-1612 LST, which corresponded to the developing stage of this supercell. From 1618 to 1706 LST, the rotational velocity and the mesocyclone altitude increased significantly. Especially after the appearance of the hook echo at 1648 LST, a moderate to strong mesocyclone was detected from the lowest 


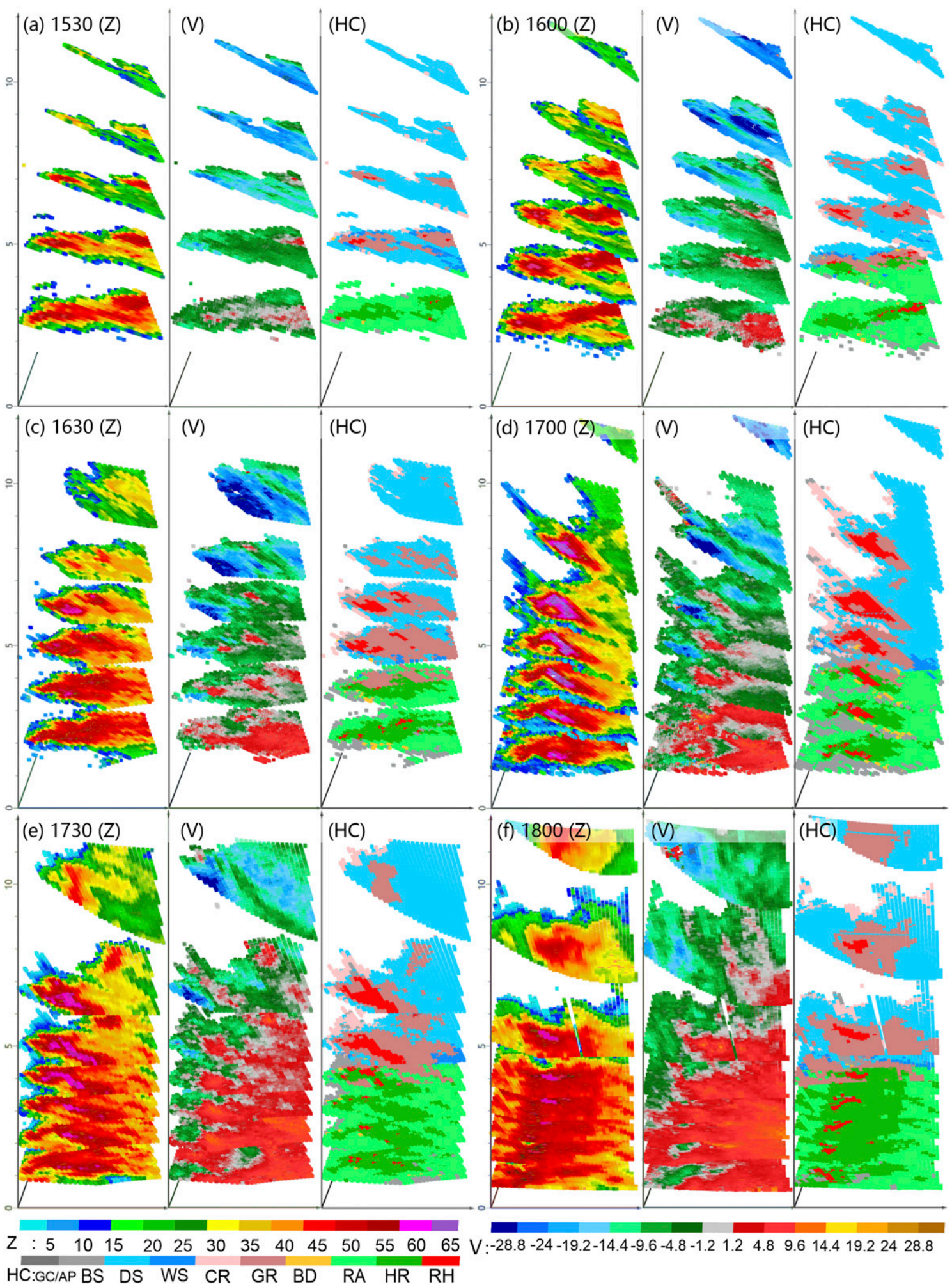

FIG. 4. The three-dimensional structures of $Z, V$, and the HCA output of SPOL at (a) 1530, (b) 1600, (c) 1630, (d) 1700, (e) 1730, and (f) 1800 LST 9 May 2016. 


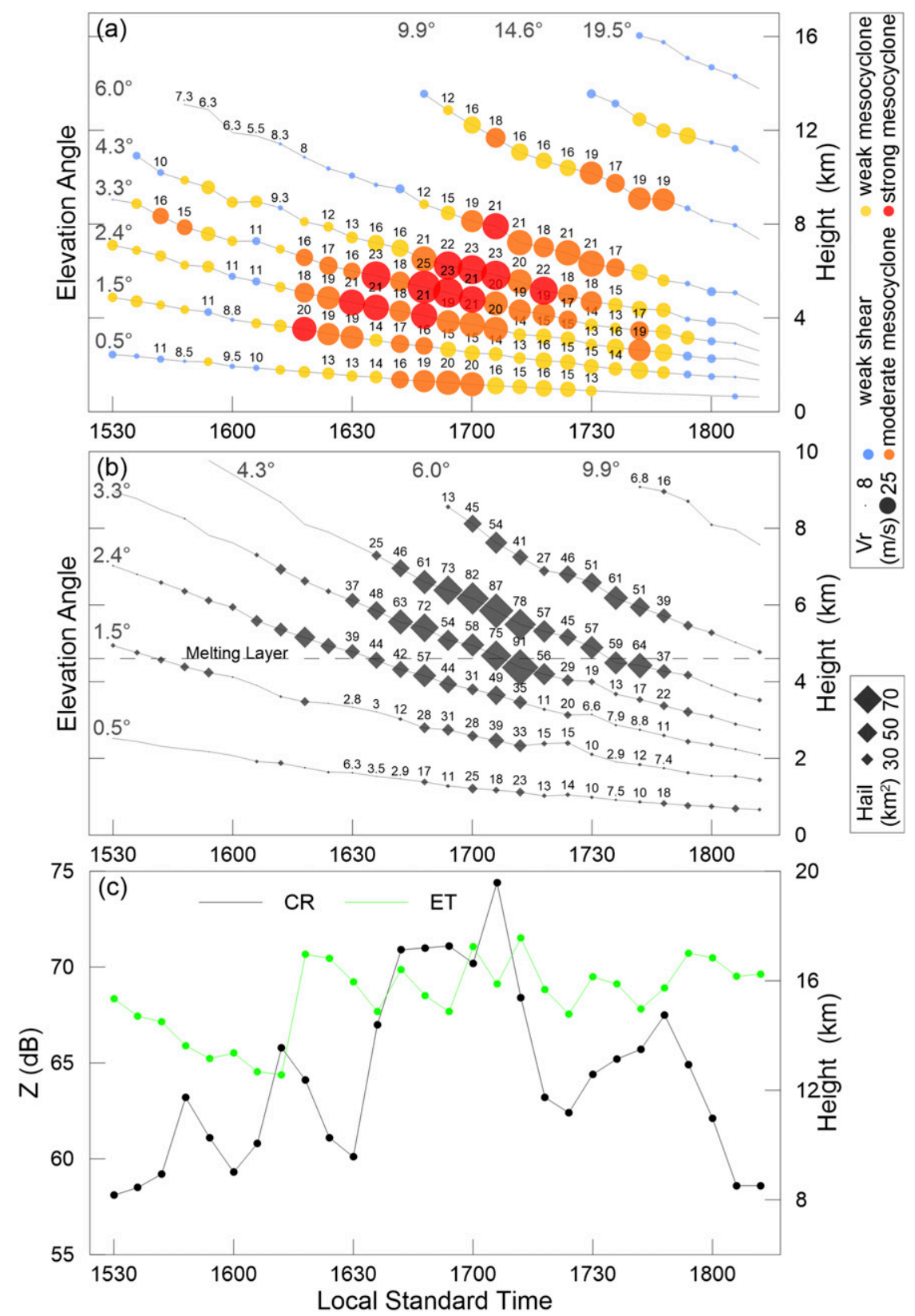

FIG. 5. Temporal evolutions of (a) the rotational velocity of the mesocyclone, (b) the RH area identified by the HCA, and (c) the output of the CR and ET algorithms observed by SPOL from elevations of $0.5^{\circ}$ to $19.5^{\circ}$ during the period of $1530-1812$ LST 9 May 2016.

observed altitude up to $12 \mathrm{~km}$, suggesting that this supercell had matured. At 1700 LST, both the rotational velocity and its altitude increased to their maximum values of $23 \mathrm{~m} \mathrm{~s}^{-1}$ and $8 \mathrm{~km}$, respectively. Afterward, the mesocyclone gradually weakened from the lower to upper levels, leaving a weak mesocyclone below a height of $3 \mathrm{~km}$. All the abovementioned features suggest that the supercell entered its dissipating stage before it eventually split and disappeared.
The tendency of the RH region identified by HCA (Fig. 5b) is basically consistent with mesocyclone development, even though there are other factors (e.g., the storm-relative flow) that can also contribute to hail growth. During the developing stage from 1530 to 1612 LST, the $\mathrm{RH}$ region above the melting layer was very small, which indicates that the updraft may not have been strong enough to support a large area of hail growth. These hailstones rapidly melted while falling and could 
not reach the ground. With the enhancement of the mesocyclone after 1618 LST, hailstones, which were sustained by a stronger updraft, existed over broader regions in the middle troposphere. When the hook echo appeared at 1648 LST, the area of the RH region above $4 \mathrm{~km}$ reached up to $70-90 \mathrm{~km}^{2}$. With a larger area of hail aloft, the area classified as RH at the lowest altitude increased up to $25 \mathrm{~km}^{2}$ at 1700 LST as the hailstones fell to the ground. Note that, during the period of 1706-1730 LST, the mesocyclone in the lower troposphere showed a continuous weakening tendency, whereas the RH area at the same height increased again, reaching its maximum value at $1712 \mathrm{LST}$, and then started to decrease. We surmise that the reason for the delaying tendency is that the hail fell toward the ground as the updraft weakened. As a result, the RH area at 1712 LST of the dissipating stage was even larger than that in the mature stage. After much of the large hail fell to the ground as the supercell dissipated, the area of $\mathrm{RH}$ observed by SPOL rapidly decreased.

During the period of 1630-1706 LST, the CR increased from 60 to $75 \mathrm{dBZ}$ (Fig. 5c), concurrent with changes seen in the mesocyclone algorithm and the HCA. For other time periods, however, values of CR repeatedly varied between 60 and $65 \mathrm{~dB} Z$ and were generally not useful for observing the storm evolution. The maximum value of ET remained higher than $15 \mathrm{~km}$, which indicates that the vertical motion in this supercell was vigorous. But because of the coarse vertical sampling of the VCP21 strategy, the variation tendency of the ET product from 1530 to 1800 LST was not sufficiently obvious and cannot provide detailed characteristics for the storm evolution. Considering the stronger mesocyclone within the supercell was associated with a strengthening updraft that could support hail growth, it is reasonable that the mesocyclone algorithm and HCA were more useful than CR and ET. Moreover, the operational application of the mesocyclone algorithm is restricted by the issues of velocity ambiguity, range folding, and incorrect thresholds (Fei et al. 2016). The HCA based on polarimetric variables is a relatively convenient, straightforward, and useful algorithm for nowcasting.

\section{b. Polarimetric signatures within the supercell}

The hook echo was once considered to be the bestrecognized feature of a supercell, but more polarimetric signatures, such as the $Z_{\mathrm{DR}}$ arc, $K_{\mathrm{DP}}$ foot, and midlevel $Z_{\mathrm{DR}} / \rho_{\mathrm{hv}}$ rings, have subsequently been observed in the United States (e.g., Loney et al. 2002; Kumjian and Ryzhkov 2008; Romine et al. 2008; Kumjian and Ryzhkov 2009; Payne et al. 2010; Snyder et al. 2013). For this supercell, which occurred in southern China, most of the abovementioned features were also observed by SPOL. Figure 6 shows the three-dimensional structures of $Z, V, Z_{\mathrm{DR}}, \rho_{\mathrm{hv}}, K_{\mathrm{DP}}$, the standard deviation of $\Phi_{\mathrm{DP}}$ $\left[\operatorname{SD}\left(\Phi_{\mathrm{DP}}\right)\right]$, and the HCA output observed by SPOL at 1648 LST. The vertical cross sections along the hook region are also presented in Fig. 7.

The most obvious signature of hail was the very large $Z$ ( $>60 \mathrm{~dB} Z$ in Fig. $6 \mathrm{a}), Z_{\mathrm{DR}}$ ranged from -1.0 to $1.0 \mathrm{~dB}$ (Fig. 6d) because of its quasi-spherical shape, and the reduced $\rho_{\mathrm{hv}}(0.86-0.93$ in Fig. 6e) indicated hail melting or Mie scattering effects. In the vertical cross sections, the hail signature was primarily located in the echo overhang at a height of 4-7 km. Negative $K_{\mathrm{DP}}$ was found at the rear of the hailstones (the range and height are $20 \mathrm{~km}$ and $7 \mathrm{~km}$, respectively, in Fig. 7d) and was related to the backscatter differential phase of the Mie scattering. Similar negative values were found at a height of $10 \mathrm{~km}$ above the hailstones, where $Z$ ranged from 30 to $45 \mathrm{dBZ}$ and $\rho_{\mathrm{hv}}$ was close to 1 , corresponding to graupel. A narrow belt with enhanced $K_{\mathrm{DP}}\left(2^{\circ}-4^{\circ} \mathrm{km}^{-1}\right)$ was found in Fig. $7 \mathrm{~d}$, which is called the $K_{\mathrm{DP}}$ column signature. The upper part, where the environment temperature ranged from $0^{\circ}$ to $-20^{\circ} \mathrm{C}$, might be related to the positive temperature perturbation by the updraft and the wet growth of hail (Foote 1984). Some of the hail and graupel began to melt when they fell below the melting layer and formed the lower part of the $K_{\mathrm{DP}}$ column. The effect of hail melting or sublimation and rain evaporation or drag led to the formation of the forward-flank downdraft (FFD) in the northeastern part of the supercell (Klemp et al. 1981; Klemp and Rotunno 1983). The $K_{\mathrm{DP}}$ foot signature near the surface was located between the FFD and the hook region in Fig. 6f. The enhanced $K_{\mathrm{DP}}$ $\left(3^{\circ}-4^{\circ} \mathrm{km}^{-1}\right)$ and $\rho_{\mathrm{hv}}(0.97-0.99)$ indicated that this region was likely composed of heavy rainfall with high water content from melted hail and graupel. The "threebody scatter spike" (TBSS) in Fig. 6a is another signature associated with hail and is a virtual echo caused by multiple scatters between the hail and the ground (Lemon 1998; Hubbert and Bringi 2000). The polarimetric variables of TBSS, abnormal $Z_{\mathrm{DR}}$ (from -4 to $7 \mathrm{~dB}$ in Fig. 6d), low $\rho_{\text {hv }}\left(0.1-0.5\right.$ in Fig. 6e), negative $K_{\mathrm{DP}}$ (from $-7^{\circ}$ to $1^{\circ} \mathrm{km}^{-1}$ in Fig. 6f), and large $\mathrm{SD}\left(\Phi_{\mathrm{DP}}\right)$ $\left(10^{\circ}-60^{\circ}\right.$ in Fig. $\left.6 \mathrm{~g}\right)$ were completely different from those of normal meteorological scatterers (Mahale et al. 2014). Note that similar features appeared above a height of $13 \mathrm{~km}$ in the vertical cross sections (at a range of $15 \mathrm{~km}$ in Figs. $7 \mathrm{a}-\mathrm{c}$ ); however, the nearby hail/graupel was located beneath this region. This feature was likely caused by scattering between the radar sidelobe and the hailstones.

The mesocyclone accompanying the hook echo was located on the southwestern side of this supercell (Figs. 6a and 6c). The positive value radial velocity associated with an area of rotation at the base of the mesocyclone seemed to be related to the low-level inflow, 


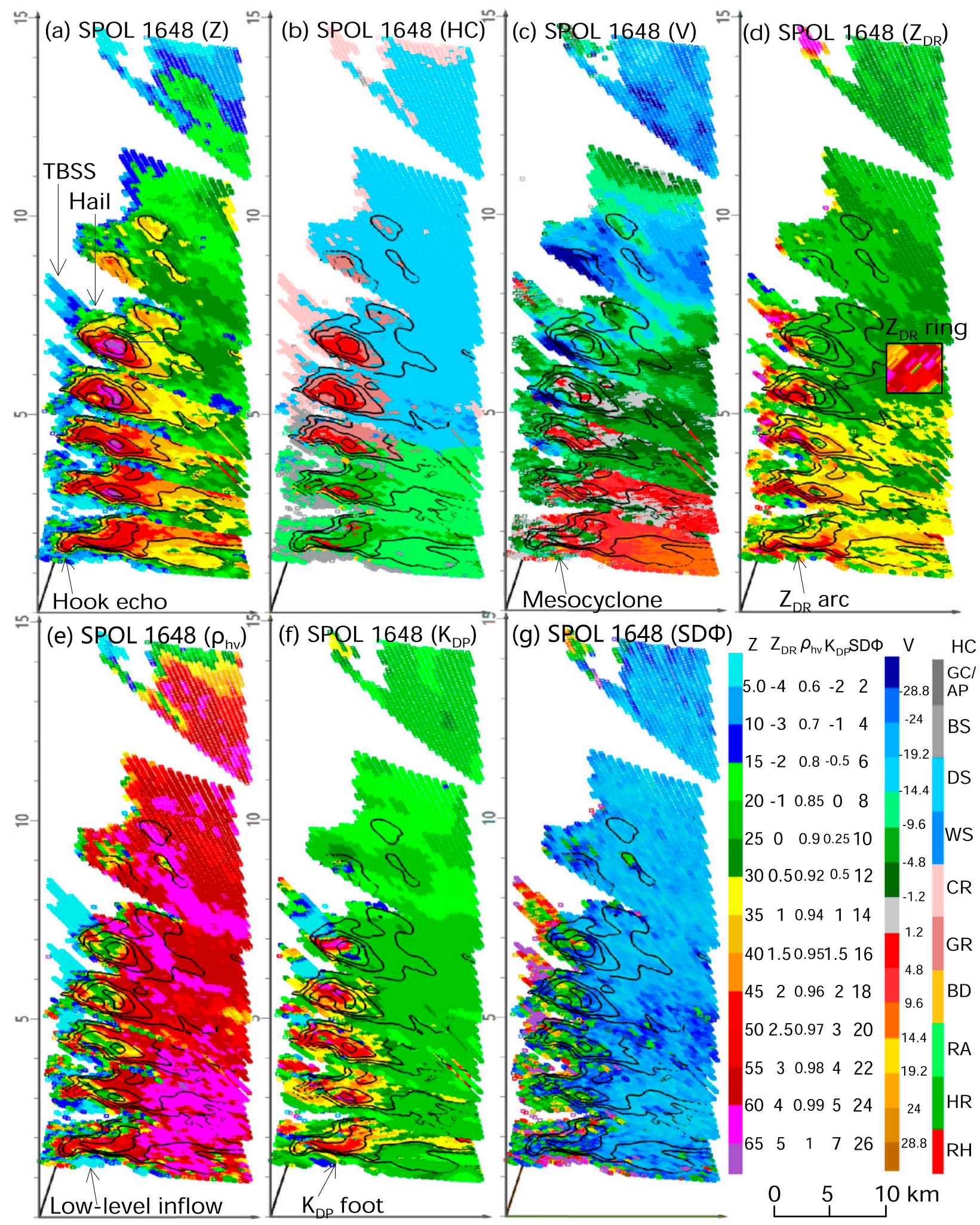

FIG. 6. The three-dimensional structures of (a) $Z$, (c) $V$, (d) $Z_{\mathrm{DR}}$, (e) $\rho_{\mathrm{hv}}$, (f) $K_{\mathrm{DP}}$, and (g) $\mathrm{SD}\left(\Phi_{\mathrm{DP}}\right.$ ), and the output from (b) HCA at 1648 LST 9 May 2016, where the radar signatures of the hook echo, hail, TBSS, $Z_{\mathrm{DR}}$ arc, $Z_{\mathrm{DR}}$ ring, and $K_{\mathrm{DP}}$ foot are clearly visible and marked. Contours of $Z(30,40,50$, and $60 \mathrm{~dB} Z)$ are overlaid on each of the figures to provide reference. 

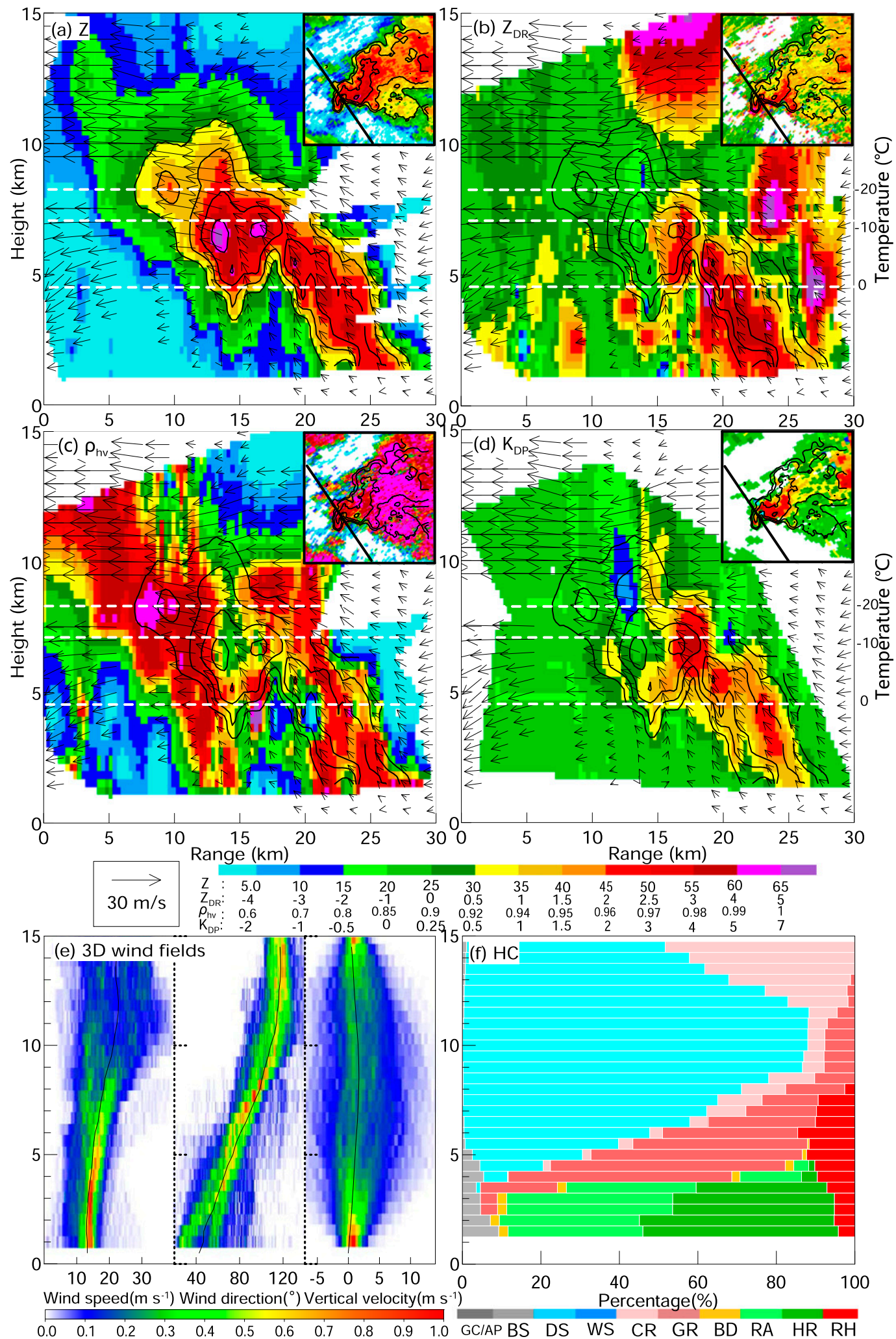

FIG. 7. The vertical cross sections of (a) $Z$, (b) $Z_{\mathrm{DR}}$, (c) $\rho_{\mathrm{hv}}$, and (d) $K_{\mathrm{DP}}$ at 1648 LST 9 May 2016. The threedimensional wind fields from CEDRIC and the contours of $Z(30,40,50$, and $60 \mathrm{dBZ})$ are overlaid on each of the panels. The insets show where the cross section is taken in the lowest-level PPI scan. The normalized frequency 
whereas the negative value radial velocity was related to the rear-flank downdraft (RFD). There was a very strong updraft $\left(>10 \mathrm{~m} \mathrm{~s}^{-1}\right.$ in Fig. $\left.7 \mathrm{a}\right)$ within the mesocyclone, forming a bounded weak echo region (BWER) beneath the echo overhang. Signatures of the low-level inflow and updraft were located in the BWER. Strong winds, debris, dusts, or insects may have been incorporated into the updraft without any large raindrops. Here $Z$ was less than $15 \mathrm{~dB} Z$ and $\rho_{\mathrm{hv}}$ was reduced to $0.45-0.8$. Because the SNR here ranged from 7 to $16 \mathrm{~dB}$, it is also possible that the $\rho_{\mathrm{hv}}$ value was contaminated by the inconsistency between the two channels of the SPOL receiver. In the HCA output (Fig. 6b), the majority of the updraft signatures were classified as BS because $\rho_{\mathrm{hv}}$ and $\operatorname{SD}\left(\Phi_{\mathrm{DP}}\right)$ are two key variables for the identification of nonmeteorological echoes.

At the leading edge of the hook echo, the size sorting effect resulting from the strong updraft led the value of $Z_{\mathrm{DR}}$ to exceed $2 \mathrm{~dB}$, while $Z$ ranged from 30 to $50 \mathrm{~dB} Z$ and $\rho_{\mathrm{hv}}$ remained close to 1 , which might be related to the presence of very large raindrops. This signature is called the $Z_{\mathrm{DR}}$ arc and was located on the southwestern edge of the first layer (Kumjian and Ryzhkov 2007; Dawson et al. 2014). The large value region of the $Z_{\mathrm{DR}}$ extended from the surface to a height of $6-7 \mathrm{~km}$, forming a $Z_{\mathrm{DR}}$ column signature similar to the $K_{\mathrm{DP}}$ column signature (Kumjian et al. 2014; Snyder et al. 2015). However, a comparison between Figs. $7 \mathrm{~b}$ and $7 d$ shows that the spatial distributions of the two abovementioned signatures were not entirely consistent. The partial superposition of the $K_{\mathrm{DP}}$ column and the $Z_{\mathrm{DR}}$ column was composed of melting hail and heavy rainfall with higher $Z, Z_{\mathrm{DR}}$, and $K_{\mathrm{DP}}$ values. However, large raindrops with enhanced $Z_{\mathrm{DR}}$ values at the edge of the BWER did not present peak values of $Z$ and $K_{\mathrm{DP}}$. That means that the spatial distribution of the $Z_{\mathrm{DR}}$ column was wider than that of the $K_{\mathrm{DP}}$ column. At a height of $\sim 5 \mathrm{~km}$, a small ring of enhanced $Z_{\mathrm{DR}}(2.5-4 \mathrm{~dB})$ was found surrounding the BWER in Fig. $6 \mathrm{~d}$, called the midlevel $Z_{\mathrm{DR}}$ rings (Kumjian and Ryzhkov 2008; Snyder et al. 2017a,b). On the western part of this ring, the smaller $Z(20-40 \mathrm{~dB} Z)$ and larger $\rho_{\mathrm{hv}}(0.98-0.99)$ values might indicate the presence of large raindrops carried by the updraft. Conversely, larger $Z$ (45-60 dBZ) and smaller $\rho_{\mathrm{hv}}(<0.95)$ on the eastern and northern parts of the ring indicated the existence of melting hail. These melting particles cannot exist inside the ring because of the strong airflow, and debris incorporated into the updraft might lead to low $\rho_{\mathrm{hv}}(0.7-0.8)$ inside this ring.

The normalized frequency distributions of winds and hydrometeors are shown in Figs. 7e and 7f. Strong vertical wind shear was one of the sources of supercell vertical motion by tilting the horizontal vorticity (Markowski 2016). The BD appeared at a height of 0-5 $\mathrm{km}$ accompanied by increasing vertical velocity with altitude. Above the melting layer, large proportions of DS and CR might have collided with the BD and formed GR. The GR from 5 to $12 \mathrm{~km}$ acted as hail embryos in the formation of the RH. The maximum proportion of $\mathrm{RH}$ in the vertical direction was located at a height of $6 \mathrm{~km}$, which was consistent with the height of maximum vertical velocity. Below the melting layer, the decreased proportion of RH and the increased proportion of RA and HR represented the gradual thawing of the frozen precipitation. The abovementioned information provided by the radar products is basically consistent with that of supercell signatures.

\section{c. The spatiotemporal distribution of the supercell signatures}

The horizontal and vertical distributions of the supercell signatures at 1648 LST are shown in Figs. 8a and $8 \mathrm{~b}$. The life cycle of these signatures during the period of 1530-1806 LST is also illustrated in Fig. 8c to compare to the HCA and mesocyclone products (Fig. 5). Hail signatures with large spatial scales $(>15 \mathrm{~km})$ were widespread from the near surface to midlevel in most of the supercell life cycle. When the area of RH increased to $23 \mathrm{~km}^{2}$ at $1548 \mathrm{LST}$ (Fig. 5b), the hail signature was first observed by SPOL. With the help of HCA, the hail signature can be easily identified in the $\mathrm{RH}$ region together with large areas of surrounding GR (Miller and Fankhauser 1983; Miller et al. 1988). Both the temporal and spatial distributions of the TBSS were closely related to hail. Even though the TBSS was temporarily unable to be classified by HCA, its obvious differences from meteorological echoes permitted manual identification. A TBSS that was over $20 \mathrm{~km}$ in radial extent, accompanied by large areas of RH regions in front of it, was a key feature of the large hailstones within this supercell.

During the mature stage, the lifetime of the low-level inflow signature was nearly concurrent with the time

distributions of (e) the three-dimensional wind fields and (f) the HCA output counted from the hook echo region at 1648 LST. The three white dashed lines in (a)-(d) represent the levels of $0^{\circ},-10^{\circ}$, and $-20^{\circ} \mathrm{C}$, respectively, from Qingyuan sounding at 1400 LST. Black lines in (e) denote the wind profiles of averaged wind speed, wind direction, and vertical velocity within the supercell. 

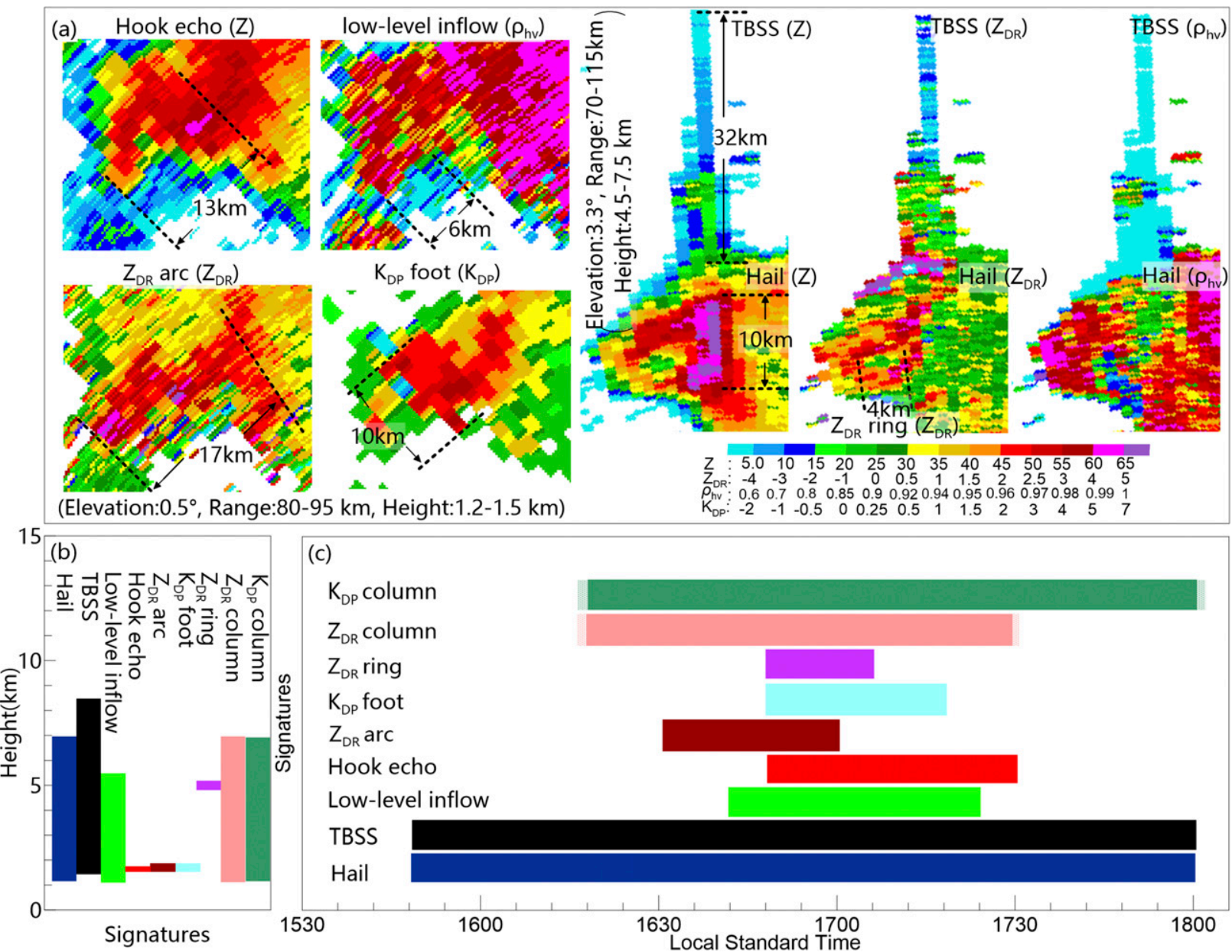

FIG. 8. The (a) horizontal, (b) vertical, and (c) temporal distributions of the radar signatures during the period of 1530-1812 LST 9 May 2016.

period when the rotational velocity of the mesocyclone was greater than $14 \mathrm{~m} \mathrm{~s}^{-1}$ (Fig. 5a). The vertical distributions of the inflow signature ranged from 0 to $5 \mathrm{~km}$ even though the horizontal scale of this signature was relatively small $(<10 \mathrm{~km})$ for its identification. The BS region ahead of the supercell with very large $V$ $\left(>15 \mathrm{~m} \mathrm{~s}^{-1}\right)$ might be a useful indicator in the HCA product. The three signatures of the hook echo, the $Z_{\mathrm{DR}}$ arc, and the $K_{\mathrm{DP}}$ foot had similar horizontal scales $(10-17 \mathrm{~km})$ and appeared only near the ground. However, their time durations were not the same because of the different causes of their formation. The hook echo was related to the inflow signature; once the inflow disappeared at 1724 LST, the hook echo disappeared. The $Z_{\mathrm{DR}}$ arc was related to the intensifying mesocyclone; once the rotational velocity began to decrease at 1700 LST, the $Z_{\mathrm{DR}}$ arc quickly became more diffuse and disappeared. The $K_{\mathrm{DP}}$ foot, which was associated with melting hail and heavy rainfall, appeared when the area of $\mathrm{RH}$ increased to more than $10 \mathrm{~km}^{2}$ in the lower troposphere.

The midlevel $Z_{\mathrm{DR}}$ ring was the shortest-lived $(\sim 18 \mathrm{~min})$ and smallest-scale $(<5 \mathrm{~km}$ in the one-layer observation) signature of this supercell; therefore, it is difficult to use these signatures in operations. But its lifetime corresponded to the moment when the supercell mesocyclone was reaching its maximum intensity. The $Z_{\mathrm{DR}}$ and $K_{\mathrm{DP}}$ columns were also apparent in the vertical direction; however, the exact times during which they formed and dissipated were difficult to confirm owing to the coarse vertical coverage of SPOL. Because large raindrops with higher $Z_{\mathrm{DR}}$ can barely exist in the dissipating stage, it is also reasonable that the life cycle of the $Z_{\mathrm{DR}}$ column was roughly shorter. In general, the supercell signatures matched the storm evolution well. It is feasible to use several of the larger and longer-lived signatures discussed above (e.g., hail, TBSS, and the $Z_{\mathrm{DR}}$ arc) for severe storm nowcasting. 


\section{Advantages of the rapid-scan capability of the phased-array radar}

a. Comparison between the phased-array and parabolic-antenna radar observations in convective storm initiation and mergers

Three necessary ingredients are important for the initiation of severe convection storms (Johns and Doswell 1992): low-level moisture, lapse rates (e.g., $d T / d z$ less than $-6.5^{\circ} \mathrm{Ckm}^{-1}$ ) supporting nonzero convective available potential energy (CAPE), and sufficient lift so that parcels can reach the level of free convection (LFC). The analysis of the Qingyuan L-band sounding found that the precipitable water was $65 \mathrm{~mm}$, the CAPE was $3660 \mathrm{~J} \mathrm{~kg}^{-1}$, and the LFC was $0.69 \mathrm{~km}$ at $1400 \mathrm{LST}$, suggesting that the environmental conditions were favorable for the initiation of a convective storm. During the time period of 1655-1714 LST, XPAR observed a convective storm that was triggered by the inflow ahead of the hook echo, rapidly developed, and eventually merged with the supercell in the 1-min update time. The horizontal structures of this storm are shown in Figs. 9a-s. From 1655 to 1658 LST, the flanking line corresponding to the position of the supercell inflow was located $10 \mathrm{~km}$ southwest of the hook echo and gradually moved to the northeast. The value of $Z$ in the flanking line ranged from 10 to $25 \mathrm{~dB} Z$ without any feature of a severe storm. At $1659 \mathrm{LST}$, an $\sim 0.3 \mathrm{~km} \times 0.075 \mathrm{~km}$ horizontal square region with $Z>30 \mathrm{~dB} Z$, as part of a new initiated storm, was observed within the flanking line (the dashed circle in Fig. 9e). The maximum $Z$ of this new storm was only $32 \mathrm{~dB} Z$. In the next $6 \mathrm{~min}$, this storm rapidly developed as a result of the support of an updraft, and the area of $Z>30 \mathrm{~dB} Z$ increased to an $\sim 3 \mathrm{~km} \times 3 \mathrm{~km}$ horizontal square with a maximum $Z$ of $50 \mathrm{~dB} Z$. This convective storm moved closer to the supercell, and a merger process started when the distance decreased to $\sim 1 \mathrm{~km}$ at 1709 LST. The horizontal scale of the new cell rapidly expanded and became embedded within the supercell from 1710 to 1713 LST, and this process completely finished at 1714 LST. For the abovementioned short time evolution, the horizontal structures of SPOL (Figs. 9t-x) were roughly consistent. But limited by the 6 -min scan cycle and the $250-\mathrm{m}$ range resolution, details were lost.

One of the major advantages of XPAR is that it can collect data at 40 different elevation angles, which provides much more vertical data coverage, aiding assessments of storm evolution. Figure 10 illustrates a comparison of the vertical structures between XPAR and SPOL. Before the new cell was triggered, only weak reflectivity corresponding to small raindrops was observed within the flanking line below a height of $4 \mathrm{~km}$. After the initiation of convective storms by an updraft in the peak inflow region at 1658 LST, a convective core $(Z>35 \mathrm{dBZ}$ ) was observed at a height of $\sim 5 \mathrm{~km}$. Both the vertical scale and the value of maximum $Z$ rapidly increased in the following $10 \mathrm{~min}$. When the merger process started at 1709 LST, the convective core was embedded in the lower part of the supercell, with the ET of the new storm decreasing from $\sim 6$ to $\sim 4 \mathrm{~km}$. After the two storms completely merged at 1714 LST, the tilted nature of the supercell was recovered. Owing to the limitation of insufficient layers in the VCP21 strategy, neither the abovementioned evolution process nor the supercell structure above $5 \mathrm{~km}$ can be accurately acquired by SPOL. Note that all the vertical structures of SPOL are more tilted than the XPAR observations. The reason for this phenomenon is that the time interval between the first and last layers of the VPPI scan was $\sim 6 \mathrm{~min}$, resulting in a poor time consistency in the vertical direction, while the VRHI scan conducted by XPAR can finish the vertical observation within $1 \mathrm{~s}$. Considering strong vertical gradients of $Z$ may often exist in severe convective storms, the VRHI scan composed of 40 elevation angles by XPAR has an advantage compared to the mechanically scanned parabolic antenna operating in VCP21.

\section{$b$. The formation and dissipation of the hook echo in the phased-array radar observations}

The hook echo is an important feature within the supercell that is often accompanied by tornadoes, gale winds, and other severe hazards. In this study, the hook echo formed at $1648 \mathrm{LST}$, lasted for $48 \mathrm{~min}$, and finally dissipated at 1736 LST. No tornado sightings were reported, but gale winds knocked down some tall trees and power lines without any casualties. The nearby radars with parabolic antennas (including SPOL and XPOL) had difficulty observing the detailed evolution of the hook echo owing to their lower spatiotemporal resolution relative to that provided by XPAR; as a phasedarray radar system, XPAR provided more detailed observations of the formation and dissipation of the hook echo. Figure 11 presents the isosurfaces of $Z$ and $V$ when the hook echo formed during the period of 1641-1648 LST.

Prior to the formation of the hook echo, a relatively smooth low-level structure was observed in the isosurface of $45 \mathrm{dBZ}$ at $1641 \mathrm{LST}$. The echo overhang appeared at a height of $4 \mathrm{~km}$; the updraft between the echo overhang and the supercell was too strong to allow the presence of large raindrops or hail, leading to the formation of the BWER and the weak echo hole (WEH) in Figs. 11f and $11 \mathrm{~g}$. A mesocyclone existed below the BWER, the isosurface of $9 \mathrm{~m} \mathrm{~s}^{-1}$ corresponding to the inflow reached an altitude of $\sim 2 \mathrm{~km}$, and the isosurface of $-10 \mathrm{~m} \mathrm{~s}^{-1}$ 

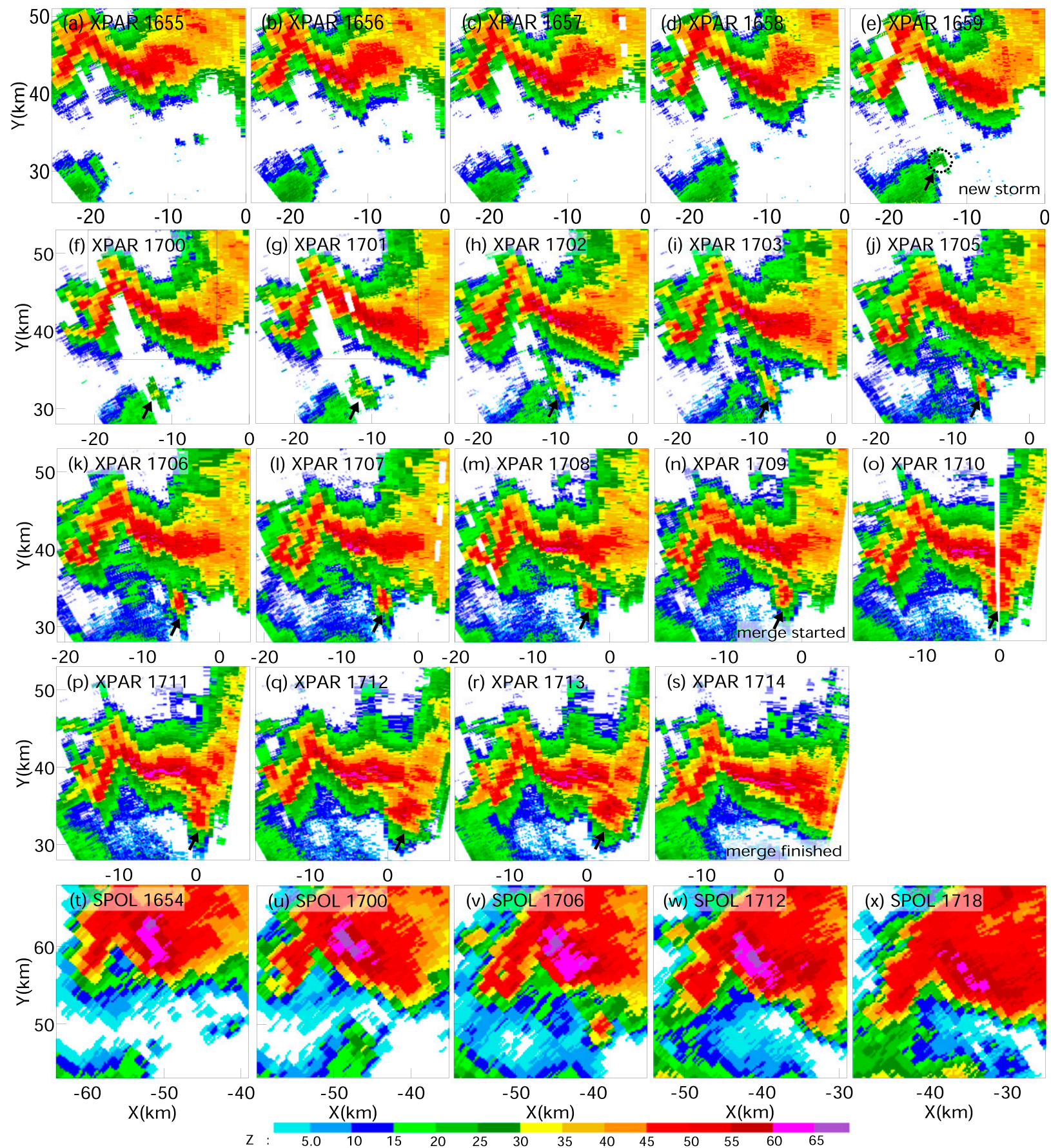

$\begin{array}{lll}-10 & 0\end{array}$

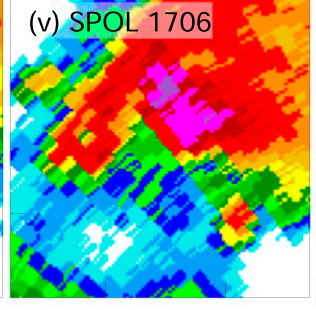

(w) SPOL 1712

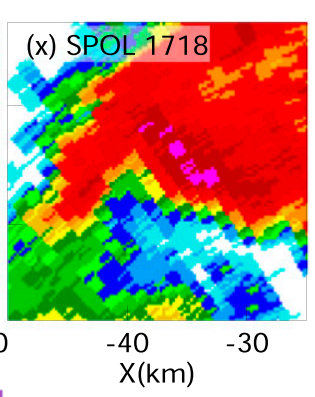

FIG. 9. The horizontal structures of $Z$ at an elevation angle of $1.5^{\circ}$ for XPAR from 1655 to 1714 LST compared to simultaneous observations by SPOL on 9 May 2016, when a new storm was triggered from the flanking line. The black dotted circle in (e) denotes the position when the new storm was first observed at 1659 LST. Black arrows in (e)-(r) point out the position and moving direction of new storm when it merged into the supercell.

on the west side was related to the outflow of the RFD. For the front part of the RFD that can be detected by XPAR (the attenuation of the X-band radar is severe in the presence of heavy precipitation), the outflow was dominant throughout the entire layer. During the time period of 1643-1644 LST, the echo overhang and BWER extended downward and the low-level structure of the supercell started to curve. The height of the positive velocity isosurface increased with the inflow intensity and reached $3 \mathrm{~km}$; meanwhile, the negative 


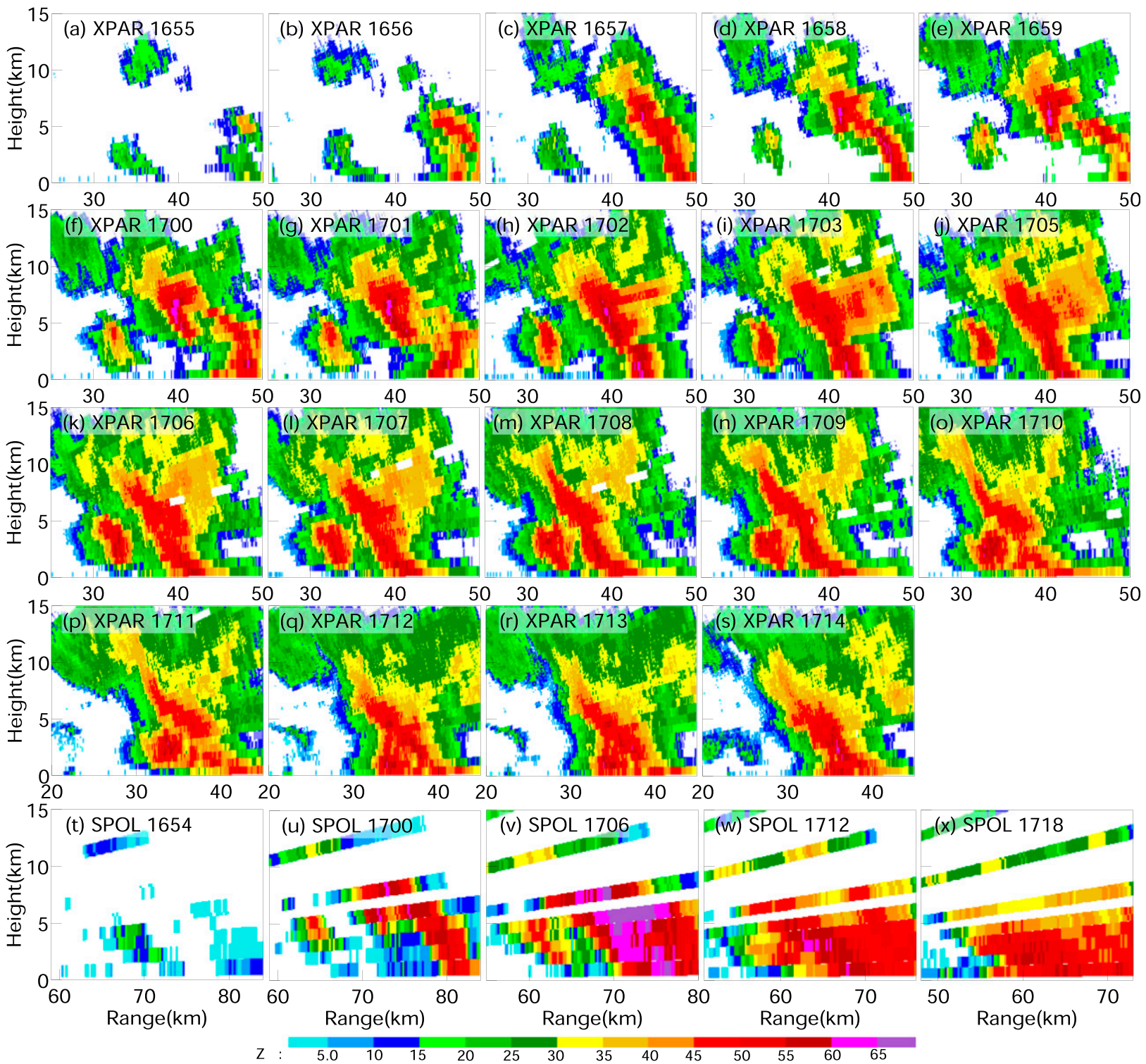

FIG. 10. As in Fig. 9, but for the vertical structures.

velocity isosurface still occupied large areas. Then, $3 \mathrm{~min}$ later at 1647-1648 LST, both the height of the $9 \mathrm{~m} \mathrm{~s}^{-1}$ isosurface and the area of the near-surface outflow continued to increase, showing an enhancement of the inflow and low-level outflow. However, the isosurface of $-10 \mathrm{~m} \mathrm{~s}^{-1}$ rapidly rose from $\sim 1$ to $\sim 3 \mathrm{~km}$, which represented a reduction in the intensity of the outflow. As a result, the strength of the inflow was predominantly contained within the mesocyclone. In the isosurface of $Z$, the supercell structure below $3 \mathrm{~km}$ was curved inward by the strong inflow, while the western edge of the supercell was curved outward by the underlying outflow, leading to the formation of an integrated hook echo at 1648 LST.
Similarly, Fig. 12 presents the dissipation process of the hook echo during the period of 1730-1736 LST. The hook echo and overhead WEH/BWER were still clearly visible at 1730 LST, and several new cells triggered by inflow were located a few kilometers ahead of the supercell. In the next $5 \mathrm{~min}$, these new cells rapidly developed to a height of $5 \mathrm{~km}$ and merged with the supercell. Meanwhile, the outline of the WEH/BEWR and the structure of the hook were gradually obscured and completely disappeared at 1736 LST. The shrinking area of the $9 \mathrm{~m} \mathrm{~s}^{-1}$ isosurface suggested a reduction in the inflow intensity accompanied by the convective merger. Conversely, the outflow from the RFD became dominant and the area of the $-9 \mathrm{~m} \mathrm{~s}^{-1}$ isosurface 

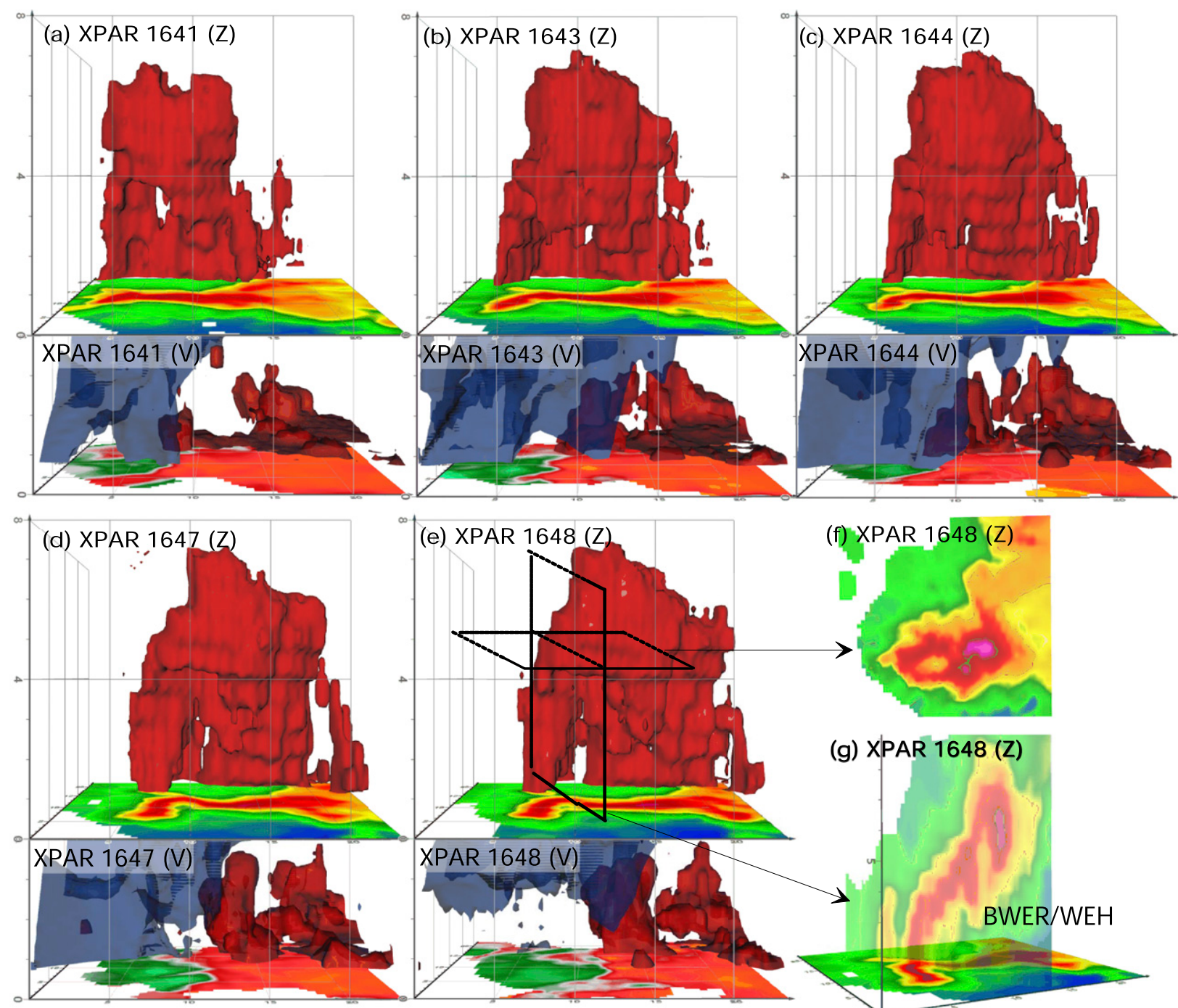

(f) XPAR $1648(Z)$

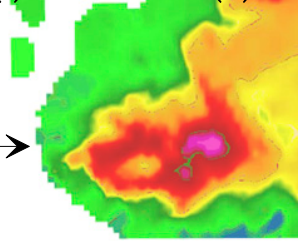

(g) XPAR $1648(\mathrm{Z})$

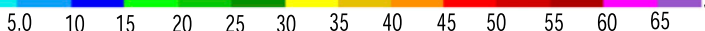

$:-24-21.6 \quad-18 \quad-14.4 \quad-10.8 \quad-7.2$

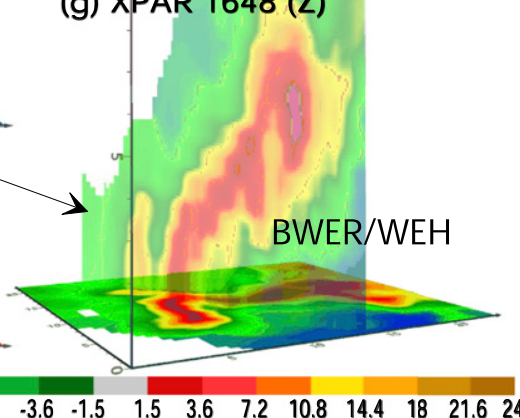

FIG. 11. The isosurfaces of $Z$ and $V$ with low-level horizontal structures of XPAR at (a) 1641, (b) 1643, (c) 1644, (d) 1647, and (e) 1648 LST when the hook echo formed. Red shading represents $45 \mathrm{~dB} Z$ for $Z$ and $9 \mathrm{~m} \mathrm{~s}^{-1}$ for $V$, and blue shading represents $-10 \mathrm{~m} \mathrm{~s}^{-1}$ for $V$. Black lines in (e) denote the direction of the (f) horizontal and (g) vertical cross sections of the supercell at 1648 LST.

gradually extended from the RFD to the inflow side. Without the support of the inflow, the curved structure of the hook echo could not be maintained any longer and completely dissipated at 1736 LST.

\section{Summary and discussion}

During SCRMEX, an S-band dual-polarization radar and an X-band phased-array radar, which represent the most advanced radar technologies in China, were deployed in the Foshan area of southern China to observe strong convective storms. SPOL had just finished a polarimetric upgrade from a single-polarization radar in March 2016. Its role is as a pilot operational radar that provides the necessary experience for dual-polarization radar projects in other parts of China. XPAR is a scientific radar for testing the performance of the phased-array system in meteorological radars and is operated only for research-based observations of convective storms. After the verification of the radar calibration, the advantages of the abovementioned dual-polarization and phased-array radars were discussed via an observational analysis of a supercell that occurred on 9 May 2016.

The presented observations show the advantage of dual-polarization radars in information gathering. The polarimetric signatures within the supercell are associated with specific microphysical processes that can 

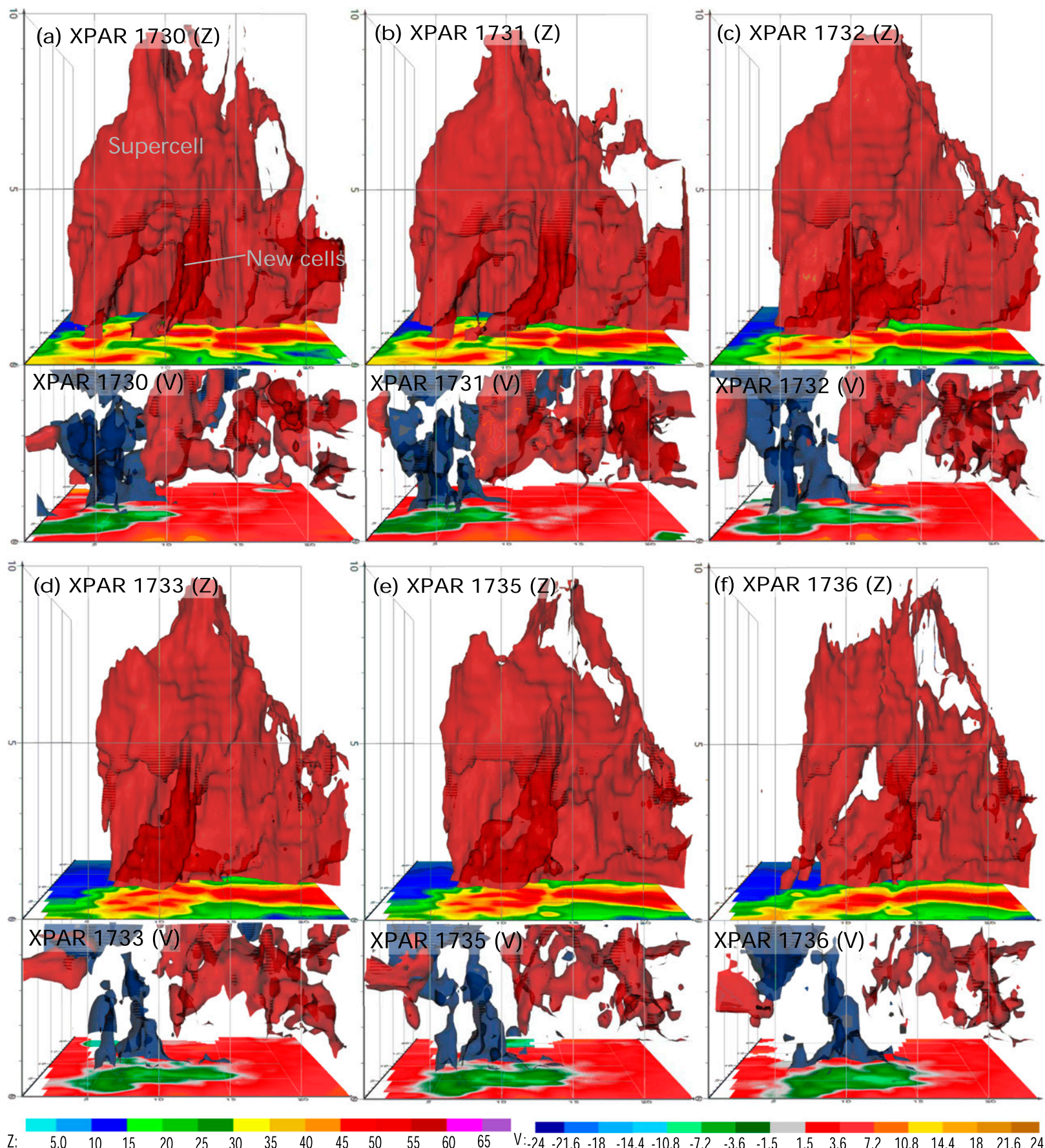

FIG. 12. As in Fig. 11, but for the dissipation of the hook echo at (a) 1730, (b) 1731, (c) 1732, (d) 1733, (e) 1735, and (f) 1736 LST. Red shading represents $40 \mathrm{~dB} Z$ for $Z$ and $14 \mathrm{~m} \mathrm{~s}^{-1}$ for $V$, and blue shading represents $-5 \mathrm{~m} \mathrm{~s}^{-1}$ for $V$.

reveal different stages of storm evolution. Some of the larger scale, longer-lived signatures (e.g., hail, TBSS, and the $Z_{\mathrm{DR}}$ arc) are also valuable for severe storm nowcasting. The HCA is a straightforward method for the consolidation of polarimetric information. A comparison of the time-varying tendencies suggests that the polarimetric classification algorithm performs more reliably in tracking the storm evolution than the conventional algorithm, which recommends it for further use in China. Even though the phased-array radar cannot provide polarimetric variables because of its present technical restrictions, its agile beams via the digital beamforming technique allow for the collection of rapid-scan data with more thorough and complete data 
in the vertical, resulting in a much higher spatiotemporal resolution. During the mature and dissipating stages of this supercell, observations from the phased-array radar show detailed changes on short time scales that cannot be observed by traditional weather radars with parabolic antennas. The initiation and mergers of new convective cells were seen in the peak inflow region, and the formation and dissipation of the hook echo were associated with the relative intensity of the inflow and outflow. The abovementioned results demonstrate that the dualpolarization and phased-array radars are promising technologies in the monitoring, nowcasting, and study of severe storms.

Limited by differences in the radar sites, wavelength, and spatiotemporal resolutions, it is difficult to simultaneously analyze observations collected by SPOL and XPAR. Therefore, the optimal means by which to integrate dual-polarization technology with phased-array technology need to be addressed before such radars can be deployed widely. The original design of the slotted array antenna restricted the polarimetric upgrade of XPAR. Over the next few years, this radar will be primarily operated for the rapid evolution analysis of severe storms in SCMREX. Meanwhile, the polarimetric upgrade of conventional radars in China should be a safe and reasonable decision before polarimetric phasedarray radars mature. When this technique is refined via Chinese meteorological radar engineering, an experiment will be designed and performed.

Acknowledgments. The authors appreciate three reviewers for their valuable suggestions and comments. No conflicts of interest were declared by the authors. This work was jointly supported by the National Natural Science Foundation of China (41675023, 91337103, 91437101) and the Scientific Research Projects of the Chinese Academy of Meteorological Sciences (2016Z005) to the second author.

\section{REFERENCES}

Anagnostou, E. N., and W. F. Krajewski, 1999: Real-time radar rainfall estimation. Part I: Algorithm formulation. J. Atmos. Oceanic Technol., 16, 189-197, https://doi.org/10.1175/ 1520-0426(1999)016<0189:RTRREP > 2.0.CO;2.

Andra, D. L., Jr., 1997: The origin and evolution of the WSR-88D mesocyclone recognition nomogram. Preprints, 28th Conf. on Radar Meteorology, Austin, TX, Amer. Meteor. Soc., 364-365.

Bluestein, H. B., M. M. French, I. PopStefanija, R. T. Bluth, and J. B. Knorr, 2010: A mobile, phased-array Doppler radar for the study of severe convective storms: The MWR-05XP. Bull. Amer. Meteor. Soc., 91, 579-600, https://doi.org/10.1175/ 2009BAMS2914.1.

Chen, B., J. Yang, and J. Pu, 2013: Statistical characteristics of raindrop size distribution in the Meiyu season observed in eastern China. J. Meteor. Soc. Japan, 91, 215-227, https:// doi.org/10.2151/jmsj.2013-208.

_ _. W. Wang, and D. Gong, 2016: Raindrop size distribution in a midlatitude continental squall line measured by Thies optical disdrometers over east China. J. Appl. Meteor. Climatol., 55, 621-634, https://doi.org/10.1175/JAMC-D-15-0127.1.

Crum, T. D., and R. L. Alberty, 1993: The WSR-88D and the WSR-88D operational support facility. Bull. Amer. Meteor. Soc., 74, 1669-1688, https://doi.org/10.1175/1520-0477(1993)074<1669: TWATWO $>2.0 . \mathrm{CO} ; 2$.

Dawson, D., E. R. Mansell, Y. Jung, L. Wicker, M. Kumjian, and M. Xue, 2014: Low-level $Z_{\mathrm{DR}}$ signatures in supercell forward flanks: The role of size sorting and melting of hail. J. Atmos. Sci., 71, 276-299, https://doi.org/10.1175/JAS-D-13-0118.1.

Elmore, K. L., 2011: The NSSL hydrometeor classification algorithm in winter surface precipitation: Evaluation and future development. Wea. Forecasting, 26, 756-765, https://doi.org/ 10.1175/WAF-D-10-05011.1.

Fei, H. Y., X. G. Zhou, and X. M. Wang, 2016: The development and application of Doppler radar mesocyclone criterion and algorithm (in Chinese). Adv. Mater. Sci. Technol., 6, 24-29.

Foote, G. B., 1984: A study of hail growth using observed storm conditions. J. Climate Appl. Meteor., 23, 84-101, https://doi.org/ 10.1175/1520-0450(1984)023<0084:ASOHGU>2.0.CO;2.

French, M. M., H. B. Bluestein, I. PopStefanija, C. A. Baldi, and R. T. Bluth, 2013: Reexamining the vertical development of tornadic vortex signature in supercells. Mon. Wea. Rev., 141, 4576-4601, https://doi.org/10.1175/MWR-D-12-00315.1.

$\longrightarrow,-,-,-$, and -2014 : Mobile, phased-array, Doppler radar observations of tornadoes at X band. Mon. Wea. Rev., 142, 1010-1036, https://doi.org/10.1175/MWR-D-13-00101.1.

Fulton, C., and Coauthors, 2017: Cylindrical polarimetric phased array radar: Beamforming and calibration for weather applications. IEEE Trans. Geosci. Remote Sens., 55, 2827-2841, https://doi.org/10.1109/TGRS.2017.2655023.

Fulton, R. A., J. P. Breidenbach, D. J. Seo, D. A. Miller, and T. O'Bannon, 1998: The WSR-88D rainfall algorithm. Wea. Forecasting, 13, 377-39, https://doi.org/10.1175/15200434(1998)013<0377:TWRA > 2.0.CO;2.

Giangrande, S. E., J. M. Krause, and A. V. Ryzhkov, 2008: Automatic designation of the melting layer with a polarimetric prototype of the WSR-88D radar. J. Appl. Meteor. Climatol., 47, 1354-1364, https://doi.org/10.1175/2007JAMC1634.1.

Heinselman, P. L., and S. M. Torres, 2011: High-temporal-resolution capabilities of the National Weather Radar Testbed Phased-Array Radar. J. Appl. Meteor. Climatol., 50, 579-593, https://doi.org/ 10.1175/2010JAMC2588.1.

- D. L. Priegnitz, K. L. Manross, T. M. Smith, and R. W. Adams, 2008: Rapid sampling of severe storms by the National Weather Radar Testbed Phased Array Radar. Wea. Forecasting, 23, 808-824, https://doi.org/10.1175/ 2008WAF2007071.1.

Hubbert, J. C., and V. N. Bringi, 2000: The effects of three-body scattering on differential reflectivity signatures. J. Atmos. Oceanic Technol., 17, 51-61, https://doi.org/10.1175/15200426(2000)017<0051:TEOTBS > 2.0.CO;2.

Isom, B., and Coauthors, 2013: The atmospheric imaging radar: Simultaneous volumetric observations using a phased array weather radar. J. Atmos. Oceanic Technol., 30, 655-675, https://doi.org/10.1175/JTECH-D-12-00063.1. 
Johns, R. H., and C. A. Doswell III, 1992: Severe local storms forecasting. Wea. Forecasting, 7, 588-612, https://doi.org/10.1175/ 1520-0434(1992)007<0588:SLSF > 2.0.CO;2.

Johnson, J. T., P. L. MacKeen, A. Witt, E. D. Mitchell, G. J. Stumpf, M. D. Eilts, and K. W. Thomas, 1998: The Storm Cell Identification and Tracking algorithm: An enhanced WSR-88D algorithm. Wea. Forecasting, 13, 263-276, https://doi.org/ 10.1175/1520-0434(1998)013<0263:TSCIAT > 2.0.CO;2.

Klemp, J. B., and R. Rotunno, 1983: A study of the tornadic region within a supercell thunderstorm. J. Atmos. Sci., 40, 359-377, https://doi.org/10.1175/1520-0469(1983)040<0359: ASOTTR $>2.0 . \mathrm{CO} ; 2$.

_ , R. B. Wilhelmson, and P. S. Ray, 1981: Observed and numerically simulated structure of a mature supercell thunderstorm. J. Atmos. Sci., 38, 1558-1580, https://doi.org/10.1175/ 1520-0469(1981)038<1558:OANSSO > 2.0.CO;2.

Kumjian, M. R., and A. V. Ryzhkov, 2007: Polarimetric characteristics of tornadic and nontornadic supercell thunderstorms. 33rd Conf. on Radar Meteorology, Cairns, QLD, Australia, Amer. Meteor. Soc., P10.1. [Available online at http://ams.confex.com/ams/pdfpapers/122882.pdf.]

- and - 2008: Polarimetric signatures in supercell thunderstorms. J. Appl. Meteor. Climatol., 47, 1940-1961, https:// doi.org/10.1175/2007JAMC1874.1.

$\longrightarrow$, and _ 2009: Storm-relative helicity revealed from polarimetric radar measurements. J. Atmos. Sci., 66, 667-685, https://doi.org/10.1175/2008JAS2815.1.

— , A. P. Khain, N. Benmoshe, E. Ilotoviz, A. V. Ryzhkov, and V. T. J. Phillips, 2014: The anatomy and physics of $Z_{D R}$ columns: Investigating a polarimetric radar signature with a spectral bin microphysical model. J. Appl. Meteor. Climatol., 53, 1820-1843, https://doi.org/10.1175/JAMC-D13-0354.1.

Kurdzo, J. M., and Coauthors, 2017: Observations of severe local storms and tornadoes with the atmospheric imaging radar Bull. Amer. Meteor. Soc., 98, 915-935, https://doi.org/10.1175/ BAMS-D-15-00266.1.

Lemon, L. R., 1998: The radar "three-body scatter spike": An operational large-hail signature. Wea. Forecasting, 13, 327-340, https://doi.org/10.1175/1520-0434(1998)013<0327:TRTBSS > 2.0. $\mathrm{CO} ; 2$.

Liu, L. P., L. L. Wu, C. Wu, X. D. Wang, X. H. Chen, J. W. Cao, and W. Zhuang, 2014: Field experiment on convective precipitation by $\mathrm{X}$-band phased-array radar and preliminary results (in Chinese). Chin. J. Atmos. Sci., 38, 1079-1094.

— C. Wu, X. D. Wang, and R. S. Ge, 2015: Test and calibration methods for X-band active phased-array weather radar (in Chinese). J. Appl. Meteor. Sci., 26, 129-140.

Loney, M. L., D. S. Zrnić, J. M. Straka, and A. V. Ryzhkov, 2002: Enhanced polarimetric radar signatures above the melting level in a supercell storm. J. Appl. Meteor., 41, 1179-1194, https:// doi.org/10.1175/1520-0450(2002)041<1179:EPRSAT>2.0.CO;2.

Luo, Y. L., and Coauthors, 2017: The Southern China Monsoon Rainfall Experiment (SCMREX). Bull. Amer. Meteor. Soc., 98, 999-1013, https://doi.org/10.1175/BAMS-D-15-00235.1.

Mahale, V. N., G. Zhang, and M. Xue, 2014: Fuzzy logic classification of S-band polarimetric radar echoes to identify threebody scattering and improve data quality. J. Appl. Meteor. Climatol., 53, 2017-2033, https://doi.org/10.1175/JAMC-D-130358.1.

Markowski, P. M., 2002: Hook echoes and rear-flank downdrafts: A review. Mon. Wea. Rev., 130, 852-876, https://doi.org/10.1175/ 1520-0493(2002)130<0852:HEARFD>2.0.CO;2.
- 2016: An idealized numerical simulation investigation of the effects of surface drag on the development of near-surface vorticity in supercell thunderstorms. J. Atmos. Sci., 73, 4349-4385, https://doi.org/10.1175/JAS-D-16-0150.1.

Meng, Z. Y., and Coauthors, 2016: Wind estimation around the shipwreck of Oriental Star based on field damage surveys and radar observations. Sci. Bull., 61, 330-337, https://doi.org/ 10.1007/s11434-016-1005-2.

Miller, L. J., and J. C. Fankhauser, 1983: Radar echo structure, air motion and hail formation in a large stationary multicellular thunderstorm. J. Atmos. Sci., 40, 2399-2418, https://doi.org/ 10.1175/1520-0469(1983)040<2399:RESAMA > 2.0.CO;2.

, J. D. Tuttle, and C. A. Knight, 1988: Airflow and hail growth in a severe northern plains supercell. J. Atmos. Sci., 45, 736-762, https://doi.org/10.1175/1520-0469(1988)045<0736: AAHGIA $>2.0 . \mathrm{CO} ; 2$

Mohr, C. G., L. J. Miller, R. L. Vaughan, and H. W. Frank, 1986: The merger of mesoscale datasets into a common Cartesian format for efficient and systematic analyses. J. Atmos. Oceanic Technol., 3, 143-161, https://doi.org/10.1175/1520-0426(1986)003<0143: TMOMDI $>2.0 . \mathrm{CO} ; 2$.

Orlanski, I., 1975: A rational subdivision of scales for atmospheric processes. Bull. Amer. Meteor. Soc., 56, 527-530, https:// doi.org/10.1175/1520-0477-56.5.527.

Park, H., A. V. Ryzhkov, D. S. Zrnić, and K.-E. Kim, 2009: The hydrometeor classification algorithm for the polarimetric WSR-88D: Description and application to an MCS. Wea. Forecasting, 24, 730-748, https://doi.org/10.1175/ 2008WAF2222205.1.

Payne, C. D., T. J. Schuur, D. R. MacGorman, M. I. Biggerstaff, K. M. Kuhlman, and W. D. Rust, 2010: Polarimetric and electrical characteristics of a lightning ring in a supercell storm. Mon. Wea. Rev., 138, 2405-2425, https://doi.org/10.1175/2009MWR3210.1.

Romine, G. S., D. W. Burgess, and R. B. Wilhelmson, 2008: A dualpolarization-radar-based assessment of the 8 May 2003 Oklahoma City area tornadic supercell. Mon. Wea. Rev., 136, 2849-2870, https://doi.org/10.1175/2008MWR2330.1.

Ryzhkov, A. V., 2007: The impact of beam broadening on the quality of radar polarimetric data. J. Atmos. Oceanic Technol., 24, 729-744, https://doi.org/10.1175/JTECH2003.1.

, T. J. Schuur, D. W. Burgess, P. L. Heinselman, S. E. Giangrande, and D. S. Zrnić, 2005: The Joint Polarization Experiment: Polarimetric rainfall measurements and hydrometeor classification. Bull. Amer. Meteor. Soc., 86, 809-824, https://doi.org/10.1175/BAMS-86-6-809.

Saeidi-Manesh, H., and G. Zhang, 2017: Characterization and optimization of cylindrical polarimetric array antenna patterns for multi-mission applications. Prog. Electromagn. Res., 158, 49-61, https://doi.org/10.2528/pier16122804.

Schuur, T. J., H.-S. Park, A. V. Ryzhkof, and H. D. Reeves, 2012: Classification of precipitation types during transitional winter weather using the RUC model and polarimetric radar retrievals. J. Appl. Meteor. Climatol., 51, 763-779, https://doi.org/ 10.1175/JAMC-D-11-091.1.

Snyder, C., and F. Zhang, 2003: Assimilation of simulated Doppler radar observations with an ensemble Kalman filter. Mon. Wea. Rev., 131, 1663-1677, https://doi.org/10.1175//2555.1.

Snyder, J. C., and A. V. Ryzhkov, 2015: Automated detection of polarimetric tornadic debris signatures using a hydrometeor classification algorithm. J. Appl. Meteor. Climatol., 54, 1861-1870, https://doi.org/10.1175/JAMC-D-15-0138.1.

, H. B. Bluestein, V. Venkatesh, and S. J. Frasier, 2013: Observations of polarimetric signatures in supercells by an 
X-band mobile Doppler radar. Mon. Wea. Rev., 141, 3-29, https://doi.org/10.1175/MWR-D-12-00068.1.

, A. V. Ryzhkov, M. R. Kumjian, A. P. Khain, and J. Picca, 2015: A $Z_{\mathrm{DR}}$ column detection algorithm to examine convective storm updrafts. Wea. Forecasting, 30, 1819-1844, https://doi.org/ 10.1175/WAF-D-15-0068.1.

— , H. B. Bluestein, D. T. Dawson, and Y. Jung, 2017a: Simulations of polarimetric, X-band radar signatures in supercells. Part I: Description of experiment and simulated $\rho_{\mathrm{hv}}$ rings. J. Appl. Meteor. Climatol., 56, 1977-1999, https://doi.org/ 10.1175/JAMC-D-16-0138.1.

$-, \ldots, \ldots$, and $\longrightarrow, 2017 \mathrm{~b}$ : Simulations of polarimetric, X-band radar signatures in supercells. Part II: $Z_{\mathrm{DR}}$ columns and rings and $K_{\mathrm{DP}}$ columns. J. Appl. Meteor. Climatol., 56, 2001-2026, https://doi.org/10.1175/JAMC-D-16-0139.1.

Stumpf, G. J., A. Witt, E. D. Mitchell, P. L. Spencer, J. Johnson, M. D. Eilts, K. W. Thomas, and D. W. Burgess, 1998: The National Severe Storms Laboratory mesocyclone detection algorithm for the WSR-88D. Wea. Forecasting, 13, 304-326, https:// doi.org/10.1175/1520-0434(1998)013<0304:TNSSLM>2.0.CO;2.

Tang, Q., H. Xiao, C. Guo, and L. Feng, 2014: Characteristics of the raindrop size distributions and their retrieved polarimetric radar parameters in northern and southern China. Atmos. Res., 135-136, 59-75, https://doi.org/10.1016/j.atmosres.2013.08.003.

Wen, L., K. Zhao, G. Zhang, M. Xue, B. Zhou, S. Liu, and X. Chen, 2016: Statistical characteristics of raindrop size distributions observed in East China during the Asian summer monsoon season using 2-D video disdrometer and Micro Rain Radar data. J. Geophys. Res. Atmos., 121, 2265-2282, https://doi.org/ 10.1002/2015JD024160.

Witt, A., M. D. Eilts, G. J. Stumpf, J. T. Johnson, E. D. Mitchell, and K. W. Thomas, 1998: An enhanced hail detection algorithm for the WSR-88D. Wea. Forecasting, 13, 286-303, https://doi.org/ 10.1175/1520-0434(1998)013<0286:AEHDAF > 2.0.CO;2.

Wu, C., L. P. Liu, and Z. Q. Zhang, 2014a: Quantitative comparison algorithm between the S-band phased array radar and the CINRAD/SA and its preliminary application (in Chinese). Acta Meteor. Sin., 72, 390-401.

,,-- X. D. Wang, H. Fan, and Q. Liu, 2014b: The measurement influence of reflectivity factor based on scanning mode from phased array radar (in Chinese). J. Appl. Meteor. Sci., 4, 406-414.

,-- , M. Wei, B. Z. Xi, and M. H. Yu, 2018: Statistics-based optimization of the polarimetric radar hydrometeor classification algorithm and its application for a squall line in South China. $A d v$. Atmos. Sci., 35, 296-316, https://doi.org/10.1007/s00376-017-6241-0.

Wurman, J., D. Dowell, Y. Richardson, P. Markowski, E. Rasmussen, D. Burgess, L. Wicker, and H. B. Bluestein, 2012: The second Verification of the Origins of Rotation in Tornadoes Experiment: VORTEX2. Bull. Amer. Meteor. Soc., 93, 1147-1170, https:// doi.org/10.1175/BAMS-D-11-00010.1.

Yoshikawa, E., T. Ushio, Z. Kawasaki, S. Yoshida, T. Morimoto, F. Mizutani, and M. Wada, 2013: MMSE beam forming on fast-scanning phased array weather radar. IEEE Trans. Geosci. Remote Sens., 51, 3077-3088, https://doi.org/10.1109/ TGRS.2012.2211607.

Yu, T. Y., M. B. Orescanin, C. D. Curtis, D. S. Zrnić, and D. E. Forsyth, 2007: Beam multiplexing using the phased-array weather radar. J. Atmos. Oceanic Technol., 24, 616-626, https://doi.org/10.1175/JTECH2052.1.

Yussouf, N., and D. J. Stensrud, 2010: Impact of phased-array radar observations over a short assimilation period: Observing system simulation experiments using an ensemble Kalman filter. Mon. Wea. Rev., 138, 517-538, https://doi.org/10.1175/ 2009MWR2925.1.

Zhang, F., and J. Sun, 2004: Impacts of initial estimate and observation availability on convective-scale data assimilation with an ensemble Kalman filter. Mon. Wea. Rev., 132, 1238-1253, https://doi.org/ 10.1175/1520-0493(2004)132<1238:IOIEAO>2.0.CO;2.

Zhang, G., R. J. Doviak, D. S. Zrnić, J. Crain, D. Staiman, and Y. Al-Rashid, 2009: Phased array radar polarimetry for weather sensing: A theoretical formulation for bias corrections. IEEE Trans. Geosci. Remote Sens., 47, 3679-3689, https://doi.org/10.1109/TGRS.2009.2029332.

,,,--- R. Palmer, L. Lei, and Y. Al-Rashid, 2011: Polarimetric phased-array radar for weather measurement: A planar or cylindrical configuration? J. Atmos. Oceanic Technol., 28, 63-73, https://doi.org/10.1175/2010JTECHA1470.1.

Zhang, J., and Coauthors, 2011: National Mosaic and Multi-Sensor QPE (NMQ) system: Description, results, and future plans. Bull. Amer. Meteor. Soc., 92, 1321-1338, https://doi.org/ 10.1175/2011BAMS-D-11-00047.1.

Zhang, X. L., and Coauthors, 2016: Analysis of the EF4 tornado in Funing County, Jiangsu Province on 23 June 2016 (in Chinese). Meteor. Mon., 42, 1304-1314.

Zhang, Z. Q., and L. P. Liu, 2011: A simulation and analysis of the observation errors of cloud intensity and structure with the S-band phased array radar and the CINRAD/SA (in Chinese). Acta Meteor. Sin., 69, 729-735.

Zheng, Y. G., and Coauthors, 2016: Survey and multi-scale characteristics of wind damage caused by convective storms in the surrounding area of the capsizing accident of cruise ship "Dongfangzhixing" (in Chinese). Meteor. Mon., 42, 1-13.

Zrnić, D. S., and A. V. Ryzhkov, 1999: Polarimetry for weather surveillance radars. Bull. Amer. Meteor. Soc., 80, 389-406, https:// doi.org/10.1175/1520-0477(1999)080<0389:PFWSR>2.0.CO;2.

_ - and Coauthors, 2007: Agile-beam phased array radar for weather observations. Bull. Amer. Meteor. Soc., 88, 1753-1766, https://doi.org/10.1175/BAMS-88-11-1753.

- I. R. Ivic, C. Fulton, D. Mirkovic, G. Zhang, and Y. Zhang, 2017: Plans for weather observation and calibration with the Advanced Technology Demonstrator. 33th Conf. on Environmental Information Processing Technologies, Seattle, WA, Amer. Meteor. Soc., 6.3, https://ams.confex.com/ams/ 97Annual/webprogram/Paper313252.html. 